\title{
On the interpretation of tense in temporal adverbial clauses
}

\author{
ELISE NEWMAN $\mathbb{D}$
}

\section{]u[ubiquity press}

\author{
ABSTRACT \\ Tenses in English temporal adjunct clauses seem to show properties of both matrix \\ and embedded tenses. On the one hand, they are often argued to be interpreted with \\ respect to the time of utterance (Stump 1985; Arregui \& Kusumoto 1998; Kubota et al. \\ 2011). On the other hand, they are more constrained than matrix tenses, claimed to be \\ limited to past tense when the matrix tense is past, and present when the matrix tense \\ is future. I present evidence from the English perfect that adjunct clauses are always \\ interpreted relative to the nearest c-commanding temporal operator, which can in \\ principle give rise to both types of behaviors: adjunct tenses are interpreted relative \\ to some temporal operator if within the scope of matrix tense, or they are interpreted \\ relative to the time of utterance if they are outside the scope of matrix tense. What \\ decides between these possibilities in a given clause are syntactic and pragmatic \\ conditions on adjunction and the resulting interaction between the presuppositions \\ introduced by the adjunct clause and the meanings of the temporal connectives. \\ The result is that when the matrix clause is a non-perfect, adjunct tenses are always \\ interpreted relative to the utterance time. When the matrix clause contains a perfect, \\ however, adjunct tenses may be interpreted relative to the matrix tense operator.
}

CORRESPONDING AUTHOR: Elise Newman

MIT, US

esnewman@mit.edu

KEYWORDS:

Tense; adjunction; temporal connectives; aspect; semantics; English

TO CITE THIS ARTICLE: Newman, Elise. 2021. On the interpretation of tense in temporal adverbial clauses. Glossa: a journal of general linguistics 6(1): 12. 1-30. DOI: https://doi.org/10.5334/ gjgl.1429 


\section{INTRODUCTION}

The behavior of tense in temporal adjunct clauses poses an enduring problem for theories of tense because its profile within and across languages differs from that of complement clauses. In English, for example, adjunct tense morphology must be past in (1) and present in (2), irrespective of the temporal connective. Tenses in complement clauses, by contrast, are not so restricted.

I adopted a cat before/after/when Katie left/*leaves/*will leave. (compare I believed that Katie liked/likes/will like her cat.)

I will adopt a cat before/after/when Katie leaves/*left/*will leave. (compare I will believe that Katie liked/likes/will like her cat.)

Two central questions regarding the status of adjunct tense are as yet unresolved in the literature: (a) whether adjunct tenses are interpreted or vacuous, and (b) if adjunct tenses are interpreted, what evaluation parameter they are interpreted with respect to. This paper provides evidence from the English perfect that adjunct tenses are interpreted rather than vacuous, and shows that it is possible to derive the evaluation parameter of an adjunct tense in English from the meaning and adjunction position of the adjunct clause.

Much previous work considers two possibilities for adjunct tense interpretation in (1) and (2). Adjunct tenses are presumed to be either interpreted with respect to the time of utterance (e.g. Stump 1985; Arregui \& Kusumoto 1998; Kubota et al. 2011), or relative to some other time introduced by the matrix clause (i.e. matrix event time) (e.g. Ogihara 1996; von Stechow \& Grønn 2013). Each option is expected to make different predictions for each temporal connective. The meaning of after, for example, orders the adjunct event prior to the matrix event. In (1), an adjunct past tense evaluated with respect to either the matrix event time or the utterance time is therefore compatible with the truth conditions of after clauses. By contrast, the meaning of before is not compatible with an adjunct past tense that is interpreted relative to the matrix event time, because before requires the adjunct event to be in the future of the matrix event. Thus, the adjunct past in before clauses must be interpreted relative to the time of utterance.

To maintain a uniform analysis of adjunct tense in (1), we could stipulate that adjunct tenses are always interpreted relative to the time of utterance in English (see e.g. Kubota et al. 2011). This readily explains why adjunct past is always the choice in (1), despite the fact that each temporal connective asserts a different temporal ordering between the matrix and adjunct event times. A similar move also explains the uniform absence of adjunct past in (2), despite the fact that an adjunct past interpreted relative to the matrix event time is always compatible with the truth conditions of after clauses. If adjunct past is always interpreted with respect to the time of utterance, an adjunct event that occurs in the future should never be introduced with past morphology.

A problem for this approach is the availability of adjunct past in (3), which is used to introduce an adjunct event that is in the future. In (3), the past tense in the adjunct clause seems to be interpreted with respect to the future time introduced by woll rather than the utterance time (or the matrix event time).

Context: Katie and her brother are young children planning their futures. They both want to get a PhD and complete their PhDs by the time Katie is 30 . Additionally, they want Katie to get her $\mathrm{PhD}$ after/before/when her brother gets his.

If all goes according to plan, by the time she is 30 , Katie will have gotten her PhD after/before/when her brother did.

What is puzzling about the contrast between (2) and (3) is that the matrix clause in each example introduces a future time, relative to which an adjunct past can in principle be interpreted. However, adjunct past is only accepted if the matrix clause also contains the perfect, which cannot be explained by stipulating an evaluation parameter for English adjunct tenses.

On the basis of examples like (3), I will argue that adjunct tenses can in principle be interpreted relative to matrix temporal operators such as tense and aspect. I propose, however, that they are often interpreted with respect to the time of utterance due to conditions on redundant 
or contradictory meanings, which require adjunct tenses to be interpreted higher than their base adjunction positions. On the proposed theory, the apparently different evaluation times in (1) and (2) vs. (3) are not stipulated, but follow from the assumptions about adjunction, the meanings of the temporal connectives and tense operators, and the pragmatics of inferences associated with temporal adjunct clauses.

The result is that adjunct tenses in the context of matrix non-perfects (e.g. (1), (2)) are interpreted with respect to the time of utterance, because there are no adjunction positions within the scope of matrix tense that result in a meaningful interpretation of an adjunct tense. Conversely, adjunct tenses in matrix perfects (e.g. 3)) are interpreted relative to the matrix tense operator because the meaning of the perfect ameliorates the conditions blocking an adjunction position below matrix tense.

A summary of the proposal is as follows: the adjunct clause introduces the runtime of a presupposed event (Heinämäki 1974; Stump 1985; Beaver \& Condoravdi 2003; Condoravdi 2010; Iatridou 2014, among others). When that run time is depends on where the clause is located at LF. Some choices will lead to redundancy or contradiction with the content of before/after/when. As we will see, an effort to avoid redundancy and contradiction guides the movement of the clause. The perfect expands the clausal spine, and makes room for a QR position below matrix tense that is not available in non-perfect matrix clauses.

The paper is organized as follows: Section 2 details the proposed framework for tense interpretation in matrix and adjunct clauses. Section 3 discusses the meanings and syntax of temporal connectives when they select for tensed clausal complements. Section 4 demonstrates how the proposal correctly predicts the distribution of adjunct past in future perfect and non-perfect contexts. Section 5 addresses the status of adjunct present tense and demonstrates how the proposal correctly predicts its distribution on the assumption that adjunct present is an underlying future. Lastly, Section 6 argues against alternative proposals that treat English adjunct tenses as vacuous.

\section{INTERPRETING MATRIX AND ADJUNCT TENSES}

I adopt a Priorean tense system (cf. von Stechow \& Beck 2015) expressed with the indexation conventions outlined in von Fintel \& Iatridou (2019). Like in Dowty (1982) this system makes use of an index on the right that is shifted, and one on the left that keeps track of the context. Each index represents a world-time pair: the right index (i) represents the evaluation world and time, and the left index $(u)$ represents the utterance world and time. The rule in (5) sets the highest evaluation index as identical to the utterance world and time, thus ensuring that (unembedded) sentences are interpreted as claims about the context in which they are uttered. For example, given the interpretation in (4) and the rule in (5), an utterance of Katie left will situate Katie's leaving in the past relative to the time of utterance.

$u \llbracket$ PAST Katie leave $\rrbracket^{i}=1$ iff $\exists$ t: Katie leaves in $\mathrm{w}_{i}$ at $\mathrm{t}$ and $\mathrm{t}<\mathrm{t}_{i}$

Utterance Rule: An utterance of a sentence $\varphi$ that is made in a world $\mathrm{w}$ at a time $\mathrm{t}$ counts as true iff $\left\langle w, t>\llbracket \varphi \rrbracket^{<w, t>}=1\right.$.

Following von Fintel \& Iatridou (2019), who build off of insights by Iatridou et al. (2001), I assume the meanings in (6), (7), and (9) for English tense, aspect, and the perfect. These definitions take as an assumption the proposed description of tense and aspect advanced by Klein (1994). In this system, aspect locates the run time of an event with respect to an intermediate interval, which is related to the utterance time via tense. This is captured by the nature of this system - structurally lower temporal operators take as their evaluation index the output of the next highest operator (i.e. they are bound by the next highest operator). Since we will not be discussing worlds until Section 3, I will refer to the world-time index as just a time index in the meanwhile, representing the evaluation time of a constituent.

(6)

$$
\begin{aligned}
& \text { Tense } \\
& \text { a. } \quad{ }^{u} \llbracket \text { PRS } \varphi \rrbracket^{t}=1 \text { iff } u \llbracket \varphi \rrbracket^{t}=1 \\
& \text { b. } \quad u \llbracket \text { PST } \varphi \rrbracket^{t}=1 \text { iff } \exists t^{\prime}<t: u \llbracket \varphi \rrbracket^{t^{\prime}}=1 \\
& \text { c. } \quad{ }^{u} \llbracket \text { FUT } \varphi \rrbracket^{t}=1 \text { iff } \exists t^{\prime}>\text { t: }{ }^{u} \llbracket \varphi \rrbracket^{t^{\prime}}=1
\end{aligned}
$$




$$
\begin{aligned}
& \text { Aspect } \\
& \text { a. } \quad{ }^{u} \llbracket \text { PFV } \varphi \rrbracket^{t}=1 \text { iff } \exists t^{\prime} \subseteq t:{ }^{u} \llbracket \varphi \rrbracket^{t^{\prime}}=1 \\
& \text { b. } \quad{ }^{u} \llbracket \operatorname{IPFV} \varphi \rrbracket^{t}=1 \text { iff } \exists t^{\prime} \supseteq \text { t: }{ }^{u} \llbracket \varphi \rrbracket^{t^{\prime}}=1
\end{aligned}
$$

For the operators we will be discussing in this paper, the utterance time will often not need to be tracked throughout a derivation because the evaluation index will govern interpretation. However, I include it here for completeness because it is necessary for the interpretation of certain adverbs, e.g. yesterday/tomorrow. These so-called deictic elements are defined thus because further embedding them appears not to shift their evaluation time in the same way as other embedded elements. ${ }^{1}$

(8)
a. Katie will believe that her cat left yesterday.
Deictic yesterday means the day before UT, not the day before belief time
b. Katie will believe that her cat left the day before.
Non-deictic day before means before belief time

In Reichenbach (1947) terms, the evaluation index of a matrix tense corresponds to the utterance time (UT), the evaluation index of aspect corresponds to the reference time (R), ${ }^{2}$ and the evaluation index of the VP corresponds to the event or situation time (E). Perfective and imperfective aspect respectively locate $\mathrm{E}$ within $\mathrm{R}$ and vice versa, and a matrix tense relates $\mathrm{R}$ to UT.

Following Iatridou et al. (2001) (and many others), I assume that the perfect is a separate maximal projection from tense and aspect, and structurally intervenes between them (as in Figure 1). This structure is evident from the order of auxiliary verbs in English, where the perfect auxiliary have both linearly precedes the imperfective auxiliary be, and also blocks be from moving to T (e.g. Katie has not been leaving early vs. *Katie is not having left early). The perfect mediates between tense and aspect by introducing another interval (i.e. an extended now or a perfect time span), bounded on the right by the output of tense (here $\mathrm{R}=$ right boundary (RB) of perfect time span).

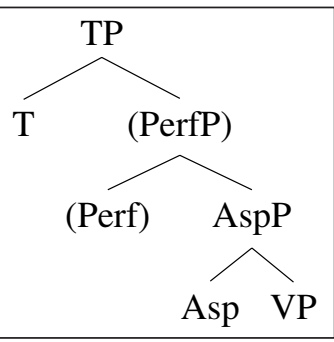

(9)

$$
{ }^{u} \llbracket \operatorname{PRF} \varphi \rrbracket^{t}=1 \text { iff } \exists t^{\prime}: t=\operatorname{RB}\left(t^{\prime}\right) \wedge u \llbracket \varphi \rrbracket^{t^{\prime}}=1
$$

In the terms of this system, a present perfect introduces an interval whose right boundary is the utterance time because the evaluation index of the English present is assigned to its complement, namely the perfect. A past or future perfect shifts the right boundary of the perfect time span to a past or future time:
Figure 1 Proposed basic clause structure.

\footnotetext{
1 It is worth noting that an embedded present tense also behaves partially like a deictic element. A sentence Katie believed that her cat is angry is only true if the cat is angry for an interval that includes both the belief time and some time at or after the utterance time, called the double access reading. This feature of the English present will not affect the main insights of this paper, but I will henceforth assume with Altshuler \& Schwarzschild (2013) that the meaning of the English present makes use of the context parameter as well as the evaluation time. 
As described by Iatridou et al. (2001), whether the perfect has a perfective or imperfective complement gives rise to different readings, which are called the existential perfect (henceforth E-perfect) and universal perfect (henceforth U-perfect) respectively. When the perfect has a perfective complement, the matrix event is understood to be contained in the perfect time span. When the perfect has an imperfective complement, the matrix event is understood to be ongoing throughout the entire perfect time span.

$$
\begin{aligned}
& \text { Katie has adopted a cat since last Tuesday. } \\
& \text { There is an adoption interval between now and last Tuesday. }
\end{aligned}
$$

Katie has been living in France since last Tuesday.

Every sub-interval between now and last Tuesday is a time at which Katie lives in France.

According to the present framework, the difference between the so-called E-perfect and $\mathrm{U}$-perfect is a natural consequence of the composition of aspect with the perfect. Aspect takes as its evaluation index the output of the perfect, namely the perfect time span. If the sister of the perfect is perfective aspect, the event time is contained inside the perfect time span. If the sister of the perfect is imperfective aspect, the event time contains the perfect time span, resulting in the two meanings in (13) and (14).

E-perfect: Katie has adopted a cat.

$\llbracket$ PRS PRF PFV Katie adopt a cat $\rrbracket^{U T}=1$ iff...

a. $\llbracket$ PRF PFV Katie adopt a cat $\rrbracket^{U T}=1$ iff..

b. $\quad \exists t: U T=R B(t) \wedge \llbracket \mathrm{PFV}$ Katie adopt a cat $\rrbracket^{t}=1$ iff...

c. $\quad \exists t: U T=R B(t) \wedge \exists t^{\prime} \subseteq t \wedge \llbracket$ Katie adopt a cat $\rrbracket \rrbracket^{\prime}=1$

d. In prose: There is some interval, bounded on the right by UT, which contains a time at which Katie adopts a cat.

$\mathrm{K}$ adopt cat

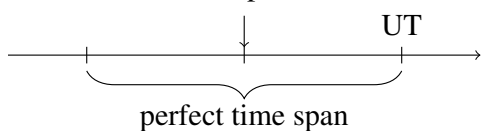

(14) U-perfect: Katie has been living in France.

$\llbracket$ PRS PRF IPFV Katie live in France $\rrbracket^{U T}=1$ iff...

a. $\llbracket P R F$ IPFV Katie live in France $\rrbracket^{U T}=1$ iff...

b. $\quad \exists t: U T=R B(t) \wedge \llbracket I P F V$ Katie live in France $\rrbracket^{t}=1$ iff...

c. $\quad \exists t: U T=R B(t) \wedge \exists t^{\prime} \supseteq t \wedge \llbracket$ Katie live in France $\rrbracket^{t^{\prime}}=1$

d. In prose: There is some interval, bounded on the right by UT, which is contained in an interval in which Katie lives in France.

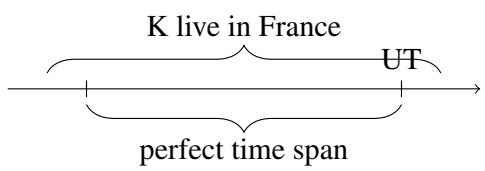

Returning to adjunct clauses, adjunction position within the matrix clause is expected to affect the evaluation index of an adjunct, which is proposed to have consequences for tense interpretation inside the adjunct clause. Since tense shifts the evaluation index of its sister, an adjunct clause that adjoins to the sister of tense will be interpreted relative to the output of the tense operator. Similarly, an adjunct clause that adjoins to the sister of the perfect (i.e. to AspP) will be interpreted relative to the output of the perfect, and so on (Figure 2). If the adjunct clause adjoins to the TP itself, however, it will be interpreted outside the scope of tense, so its evaluation index will be determined by the utterance rule (unless the clause is embedded).

Returning to the examples in (1) and (2) (repeated below), in the framework adopted here, we could imagine either of two hypotheses about the interpretation of adjunct tense. Either adjunct tenses are interpreted outside the scope of any matrix operator, and are thus interpreted with respect to (w.r.t.) the time of utterance, or they are interpreted within the scope of some matrix operator, and are thus relative to the output of that operator. On this approach, tenses are always interpreted relative to the parameter of evaluation, rather than the context index (i.e. they are not deictic), but can appear to refer to the time of utterance due to their position in the clause. 


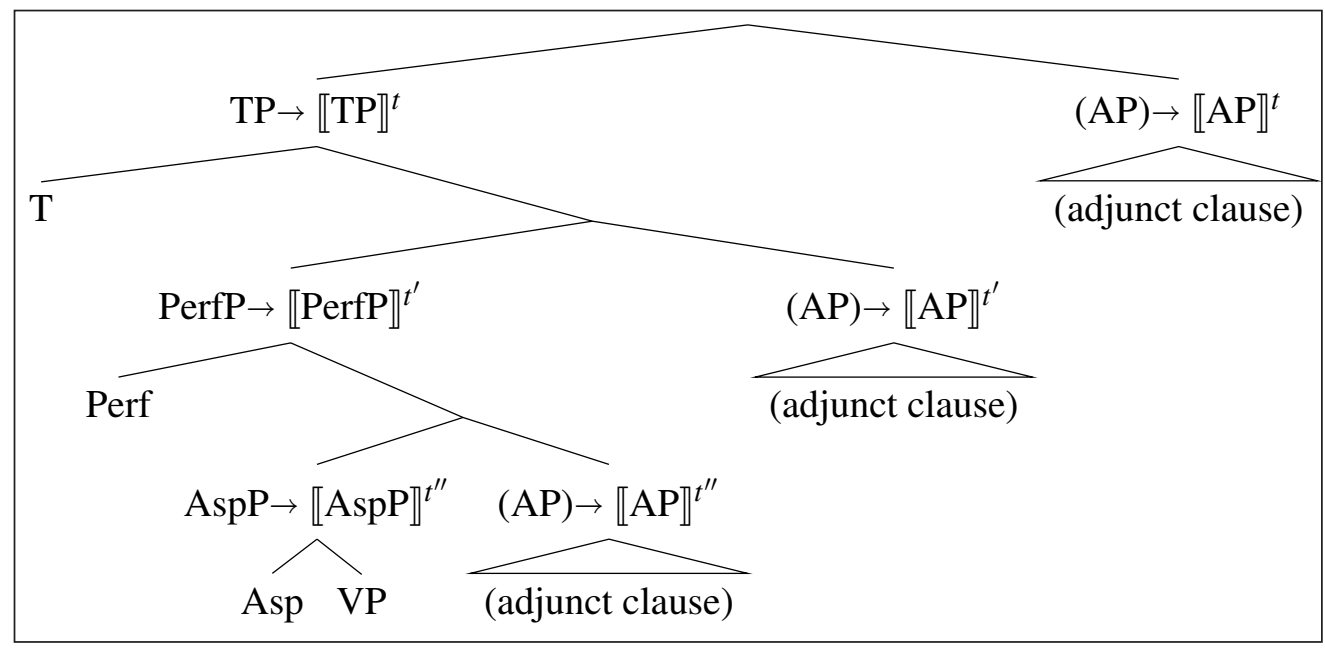

(1)

Adverbial clauses within matrix past

a. I adopted a cat when Katie left $/{ }^{*}$ leaves $/{ }^{*}$ will leave.

b. I adopted a cat before Katie left/*leaves/*will leave.

c. I adopted a cat after Katie left/*leaves/*will leave.

(2)

Adverbial clauses within matrix future

a. I will adopt a cat when Katie leaves/*left/*will leave.

b. I will adopt a cat before Katie leaves/*left/*will leave.

c. I will adopt a cat after Katie leaves/*left/*will leave.

I will argue, on the basis of evidence from the future perfect, that an LF like Figure 3 describes (1) and (2), while an LF like Figure 4 describes (3) (expanded in (15) with the full paradigm of adjunct tenses) and (16). Recall that when the matrix clause is future perfect, relative adjunct past becomes available. Not only is adjunct past available, but adjunct present is not always available - it depends on the temporal connective. In general, present perfect is preferred to present non-perfect in the adjunct clause.
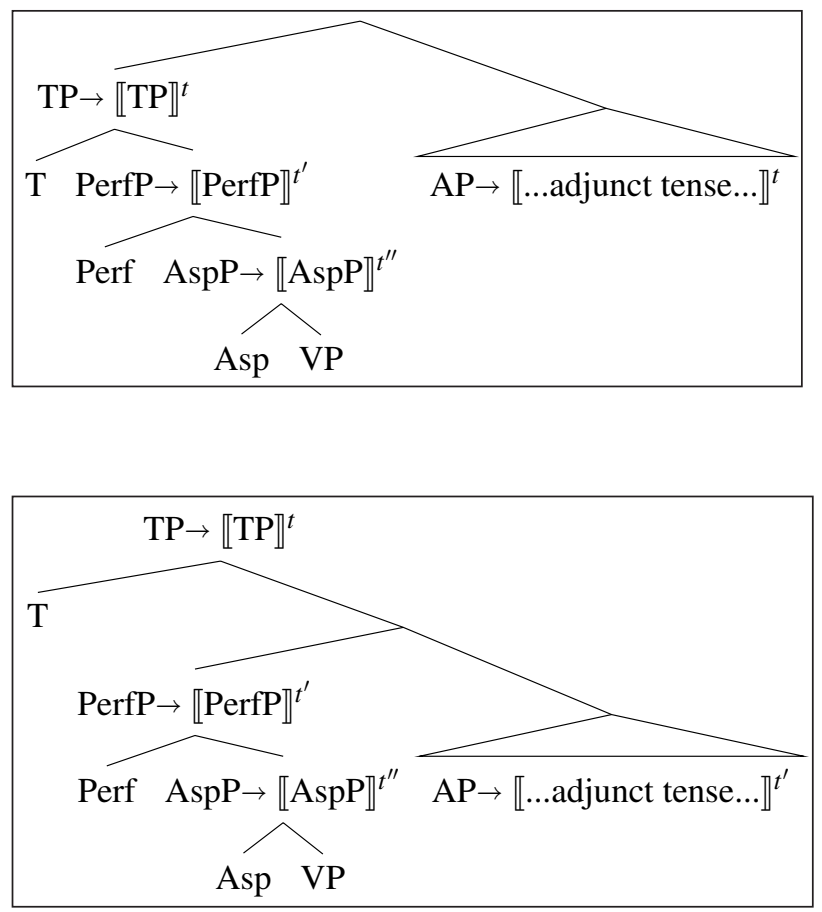

(15)

Context: Katie and her brother are young children planning their futures. They both want to get a PhD and complete their PhDs by the time Katie is 30 . Additionally, they want Katie to get her PhD after/before/when her brother gets his.
Figure 2 Adjuncts take the evaluation indices of their sisters.

Figure 3 Hypothesis 1: adjunct tenses are interpreted w.r.t. UT.

Figure 4 Hypothesis 2: adjunct tenses are interpreted relative to some other time, e.g. the output of tense. 
a. If all goes according to plan, by the time she is 30 , Katie will have gotten her PhD after her brother did/??does/has.

b. If all goes according to plan, by the time she is 30 , Katie will have gotten her PhD before her brother did/does/has.

c. If all goes according to plan, by the time she is 30 , Katie will have gotten her PhD when her brother did/?does/has.

Context: my mom plans to visit me twice before the year is over, and her first visit is scheduled to follow my future purchase of a new bike.

a. By this time next year, mom will have visited twice since I bought/*buy my new bike.

b. \%?By this time next year, mom will have visited twice since I've been riding my new bike.

Focusing on since clauses, which show the clearest contrast between adjunct past and present, observe that both $(16 a, b)$ are compatible with an interpretation in which I buy a bike and start riding it after the time of utterance. I propose that the tense inside the since clause must therefore be interpreted somewhere below matrix tense. A similar conclusion applies to before/after/when clauses. In (15), the context makes it clear that Katie's brother gets his PhD at a future time, even when the adjunct tense is past. The only difference between (15) and (16) is that adjunct present is also licensed for before/when clauses.

Sections 3 and 4 investigate the meanings of these temporal connectives in greater detail and demonstrate that Figure 5 is the LF that licenses adjunct past in future perfect contexts. In other words, relative adjunct past is always relative to the output of tense rather than the output of the perfect or aspect.

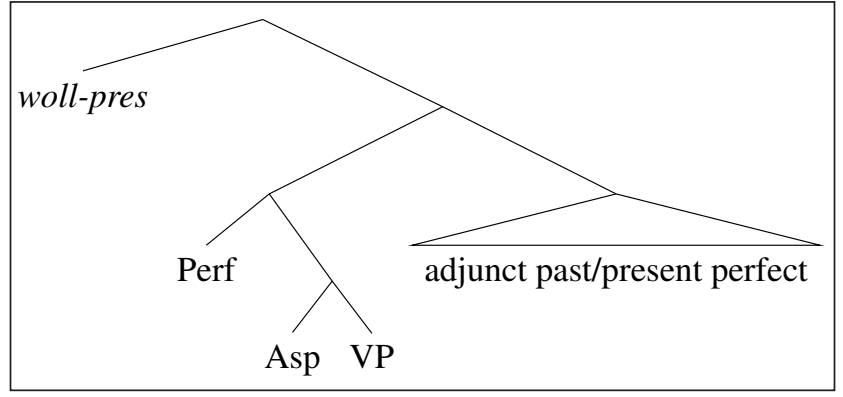

This LF is intuitively correct if we reason about the contexts in which adjunct past vs. present perfect are used. If the event inside since, for example, strictly precedes the right boundary of the perfect time span (as in Figure 6), the adjunct tense is past (16a). If the event inside since is ongoing throughout the entire interval (as in Figure 7), present perfect is licensed (16b). ${ }^{3}$ On this interpretation, adjunct tenses in $(16 a, b)$ show the profile of relative tenses, relative to the output of tense (i.e. the right boundary of the perfect time span).

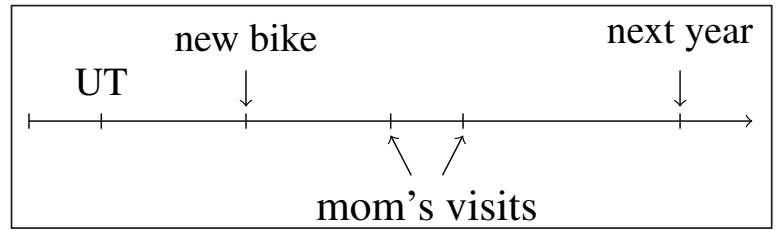

3 von Fintel \& Iatridou (2019) discuss a problem with since clauses that contain U-perfects, which is that the meaning discussed for (16b) is never predicted. The perfect time span introduced by since is predicted to be the left boundary of the matrix perfect time span, rather than ongoing throughout it. They propose that such cases are explained if since I have been riding my bike is actually since the time since which I have been riding my bike, where the second instance of since is deleted. Their insights can be readily imported into the present analysis. What is crucial for my approach is that the present perfect inside the lower since clause is sensitive to the adjunction position of the higher since clause.
Figure 5 Proposed LF for (16).

Figure 6 Past/* present inside since because the since event precedes the future time introduced by woll. 


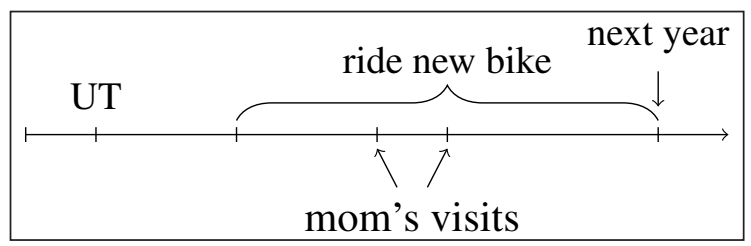

We will additionally see that the meanings of the temporal connectives require the locus of adjunct tense interpretation to be different than the adjunction position of the temporal connective itself. This is achieved if clausal complements of temporal connectives QR out of the adjunct clause to a different domain of evaluation. The LF in Figure 5 therefore represents the location of the clausal complement of since/before/after/when, not the position of those connectives themselves.

\section{TEMPORAL CONNECTIVES}

\subsection{THE MEANINGS OF TEMPORAL CONNECTIVES}

In the coming sections, I motivate a view in which the evaluation indices of adjunct tense operators are bound by matrix temporal operators. This can be achieved if temporal connectives do not, themselves, bind the evaluation indices of their complements. Following von Fintel \& Iatridou (2019), I will assume that English temporal connectives take as a complement the name of an interval. This is easiest to see when they take non-clausal complements, with a possible denotation given in (17). For now, I will focus mostly on since/before/after; when will be revisited in Section 4

In prose, since demarcates the left boundary (LB) of an interval, while before/after order their complements with respect to an interval.

$$
\begin{aligned}
& \text { a. } \quad \text { u } \llbracket \text { since } 1990 \rrbracket^{t}=1 \text { iff } u \llbracket 1990 \rrbracket^{t}=L B(t) \\
& \text { b. } \quad \text { ¿before } 1990 \rrbracket^{t}=1 \text { iff } t<u \llbracket 1990 \rrbracket^{t} \\
& \text { c. } \quad \text { uafter } 1990 \rrbracket^{t}=1 \text { iff } t>\text { u } \llbracket 1990 \rrbracket^{t}
\end{aligned}
$$

A challenge for this approach is how to unify the meanings in (17) with those of temporal connectives when they take clausal complements, which are presumably predicates of times. A resolution to this issue, following Geis (1970), Larson (1984), Romero \& von Stechow (2008), Iatridou (2014), von Fintel \& Iatridou (2019), among others, is to treat temporal adjunct clauses as relative clauses with the semantics of a definite description (Iatridou 2014), i.e. like a free relative (Jacobson 1995) (Figure 8).

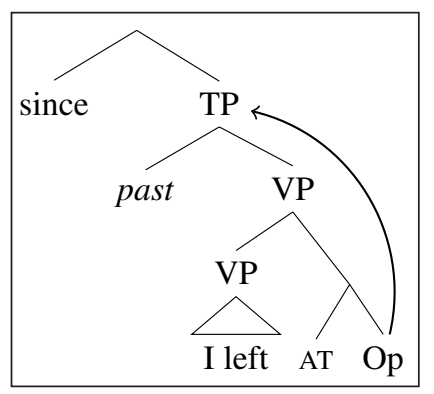

On this view, since I left should mean something like since the time at which I left. A relative clause analysis of temporal connectives has been independently motivated on the basis of so-called Geis ambiguities (Geis 1970). The observation is that the adjunct clause in both (18) and (19) behaves as though wh-movement has taken place to its edge. Adding an embedded clause within the adjunct gives rise to an attachment ambiguity, suggesting that the quantity that the temporal connectives select for originates in a lower position in the adjunct clause.

Max left before Katie told him to (leave).

Low reading: Max left before $\mathrm{x}$, where $\mathrm{x}$ is the time he should have left according to Katie's instructions.

High reading: Max left before $\mathrm{x}$, where $\mathrm{x}$ is the time at which Katie gave him leaving instructions.
Glossa: a journal of

general linguistics

DOI: $10.5334 / \mathrm{gjgl} .1429$

Figure 7 Adjunct present perfect licensed because since event now overlaps the future time introduced by woll.
Figure 8 A tensed clausal complement of since is a relative clause. 
If before clauses like (18) are relative clauses, the two readings that we observe correspond to the LFs in (20), where the base position of the operator is different for each reading. ${ }^{4}$

$$
\begin{aligned}
& \text { a. } \quad\left[\text { before }\left[\mathrm{Op} \lambda_{3} \text { Katie told him to leave at } e_{3}\right]\right] \text { (Low reading) } \\
& \text { b. } \quad\left[\text { before }\left[\mathrm{Op} \lambda_{3} \text { Katie told him at } e_{3} \text { to leave }\right]\right] \text { (High reading) }
\end{aligned}
$$

Assuming that clausal complements of temporal connectives are relative clauses, we will now discuss the meaning of the operator. Iatridou (2014) provides evidence that a clausal complement of since is a definite description because it has a uniqueness presupposition. Evidence from projection tests shows that the complement of since is presupposed. The inference associated with since's complement survives entailment cancelling operators like negation and questions. Likewise, while $(22 a)$ is a normal question to encounter on a car insurance questionaire, (22b) would be a surprise.

a. He hasn't visited Cape Cod since his cat died. $\rightarrow$ the cat died

b. Has he visited Cape Cod since his cat died? $\rightarrow$ the cat died

a. Have you been convicted of drunk driving in the last 10 years?

b. Has it been 10 years since you were convicted of drunk driving?

The uniqueness condition is evident in (23). It is infelicitous to say example (23) in a context where Max habitually insults Katie. We can rescue the sentence by adding something like the first time he insulted her.

$$
\text { Katie has adopted a cat since Max \#(first) insulted her. }
$$

On the basis of these tests, von Fintel \& Iatridou (2019) assume that the operator is like a definite article, and returns the unique time at which some predicate is true (and presupposes that there is a unique such time). This is shown in (24) (though (24) doesn't explicitly state the presupposition).

$$
\llbracket \mathrm{Op} \rrbracket^{t}=\lambda P_{i, t} \text {, the } \tau \text { such that (s.t.) } P(\tau)=1
$$

What they do not observe, however, is that interpreting a tensed clausal complement of since in situ is predicted to be contradictory on these assumptions. In prose, since I left evaluated at some time $t$ asserts the time of departure to be the left boundary of $t$, but presupposes that the time of departure precedes $t$ (because of the adjunct past).

$$
\begin{aligned}
& \text { [since I left }]=\left[\text { since }\left[\mathrm{Op}_{3}\left[\lambda_{3}\left[\text { PST PFV I leave at } e_{3}\right]\right]\right]\right] \\
& { }^{u} \llbracket \mathrm{AT} \alpha \rrbracket \rrbracket^{t}=1 \text { iff } u \llbracket \alpha \rrbracket^{t}=t \\
& \llbracket \text { since }\left[\mathrm{Op}_{3}\left[\lambda_{3}\left[\text { PST PFV I leave at } e_{3}\right]\right]\right] \rrbracket^{t, g}=1 \text { iff ... } \\
& \text { a. } \left.\quad \llbracket \mathrm{Op}_{3}\left[\lambda_{3} \text { [ PST PFV I leave at } e_{3}\right]\right] \rrbracket^{t, g}=L B(t) \\
& \text { i. } \quad=\text { the } \tau \text { s.t. } \lambda i \text {. } \llbracket \text { PST PFV I leave at } e_{3} \rrbracket^{t g(3 / i)}(\tau)=1 \\
& \text { ii. }=\text { the } \tau \text { s.t. } \exists t^{\prime}<t: \exists t^{\prime \prime} \subseteq t^{\prime} \text {. 【I leave at } e_{3} \rrbracket^{t^{\prime \prime}, g(3 / \tau)}=1 \\
& \text { iii. = the } \tau \text { s.t. } \exists t^{\prime}<t . \exists t^{\prime \prime} \subseteq t^{\prime} \text {. I leave at } \tau \wedge \tau=t^{\prime \prime}
\end{aligned}
$$

b. Result: $\tau<t$ (contribution of adjunct past) AND $\tau=L B(t)$ (contribution of since) contradiction

Choosing a different adjunct tense doesn't resolve the problem (revisited in Section 5). To avoid a contradictory interpretation on this system, since must take a different evaluation index from its complement, which can be achieved if the relative clause quantifier-raises to a higher

4 Additional motivation for this movement analysis is the fact that the different readings are island sensitive.

(i) Max left before Katie told him the story about her departure. (only high reading) 
position. If the complement of since raises, I assume it leaves behind a trace that denotes an interval. This allows us to maintain the view that tense operators inside tensed adjunct clauses are sensitive to matrix operators, and makes specific predictions about what sorts of matrix operators can bind them.

Both the meaning and syntactic requirements of since heavily constrain where the base adjunction position of the adjunct is, and therefore constrain where the adjunct tense is interpreted. I assume with McCoard (1978), Mittwoch (1988), and von Fintel \& Iatridou (2019) that since-adjuncts in English modify the left boundary of the perfect time span (Figure 9), which means that since must adjoin within the scope of the perfect. Its complement must therefore QR outside the scope of the perfect to get a meaningfully different evaluation index (Figure 10).

$\underset{\text { since } t: t=\mathrm{LB}}{\text { perfect time span }}$ RB bound by woll

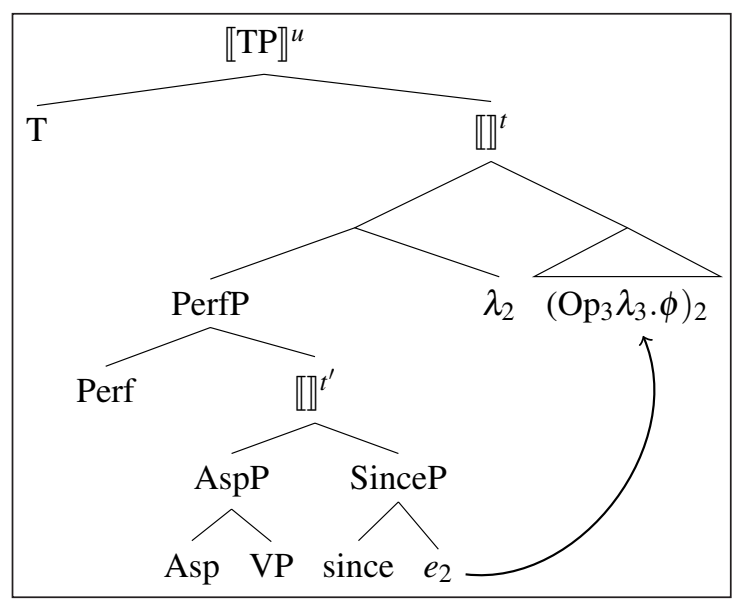

When the clause raises, the contradiction is avoided because since and the past inside it take different evaluation indices. The in situ since clause is evaluated with respect to the perfect time span, while the past inside it is evaluated with respect to the right boundary of the perfect time span.

(28)

Max will have adopted a cat since Katie left.

a. $\llbracket \lambda_{2} \mathrm{PRF}$ PFV Max adopt cat since $e_{2} \rrbracket^{t, g}=$

$\lambda \quad \lambda i . \exists t^{\prime}: t=R B\left(t^{\prime}\right) \wedge \exists t^{\prime \prime}: t^{\prime \prime} \subseteq t^{\prime}$. Max adopt cat at $t^{\prime \prime} \wedge \llbracket e_{2} \rrbracket^{\rrbracket^{\prime}, g(2 / i)}=L B\left(t^{\prime}\right)$

b. $\llbracket \mathrm{Op}_{3}\left[\lambda_{3}\left[\right.\right.$ PST PFV I leave at $\left.\left.e_{3}\right]\right] \rrbracket^{t, g}=$ the $\tau$ s.t. $\exists i^{\prime}<t . \exists i^{\prime \prime} \subseteq i^{\prime}$. Katie leave at $\tau \wedge \tau=i^{\prime \prime}$.

c. Applying (28b) to (28a)...

i. assertion: $\tau=L B\left(t^{\prime}\right)$

ii. presupposition: $\tau<t=R B\left(t^{\prime}\right)$ no contradiction!

Importing this approach to before/after, we predict that, like since, trying to interpret a past clausal complement of before with respect to the same index as before results in a contradictory interpretation. Before requires the adjunct event to follow before's evaluation index, but a past inside it would require the exact opposite ordering.

『before $\left[\mathrm{Op}_{3}\left[\lambda i\left[\right.\right.\right.$ PST PFV I leave at $\left.\left.e_{3}\right]\right] \rrbracket^{t, g}=1$ iff $\ldots$

a. $\quad t<$ the $\tau$ s.t. $\exists t^{\prime}<t . \exists t^{\prime \prime} \subseteq t^{\prime}$. I leave at $\tau \wedge \tau=t^{\prime \prime}$

b. $\quad \tau<t$ (contribution of adjunct past) AND $\tau>t$ (contribution of before) contradiction

I propose that the presuppositional nature of adjunct clauses makes them sensitive to the more general pragmatic condition in (30) (which is essentially what Schlenker (2009) has put forward, with roots and discussion in Stalnaker (1978), Singh (2007), Fox (2008), Chierchia (2009), Mayr \& Romoli (2016), Mandelkern \& Romoli (2017), among others). This condition
Glossa: a journal of

general linguistics

DOI: $10.5334 / \mathrm{gjgl} .1429$

Figure 9 Since introduces the left boundary of the perfect time span.

Figure 10 When since takes a clause, its complement is quantificational and raises to a higher position. 
renders an utterance infelicitous if the asserted content is either contradictory or redundant given its local context. This condition rules out an in situ adjunct past in a since/before clauses because the presuppositions introduced by before/since contradict their asserted content. It also rules out an in situ adjunct past in after clauses on account of redundancy - after both presupposes and asserts the same content. ${ }^{5}$

$S$ is infelicitous if, for any part $E$ of $S$, $\llbracket E \rrbracket$ is entailed or contradicted by its local context.

$$
\begin{aligned}
& \text { [after }\left[\mathrm{Op}_{3}\left[\lambda i\left[\text { PST PFV I leave at } e_{3}\right]\right]\right] \rrbracket^{t, g}=1 \text { iff } \ldots \\
& \text { a. } \quad t>\text { the } \tau \text { s.t. } \exists t^{\prime}<t . \exists t^{\prime \prime} \subseteq t^{\prime} . \text { I leave at } \tau \wedge \tau=t^{\prime \prime} \\
& \text { b. } \quad \tau<t \text { (contribution of adjunct past) AND } \tau<t \text { (contribution of after) redundant }
\end{aligned}
$$

As was demonstrated for since, the contradictory and redundant interpretations in (29) and (31) can be avoided if the complements of before/after/since are interpreted with respect to a different evaluation index than their selecting heads (Figure 11). Before demonstrating this in Section 4, however, it is important to acknowledge that the pragmatic motivations for this analysis are based on the assumption that the complements of before/after are presupposed like the complements of since are. Since this is a debated assumption, we now address the motivation for treating before/after like since.

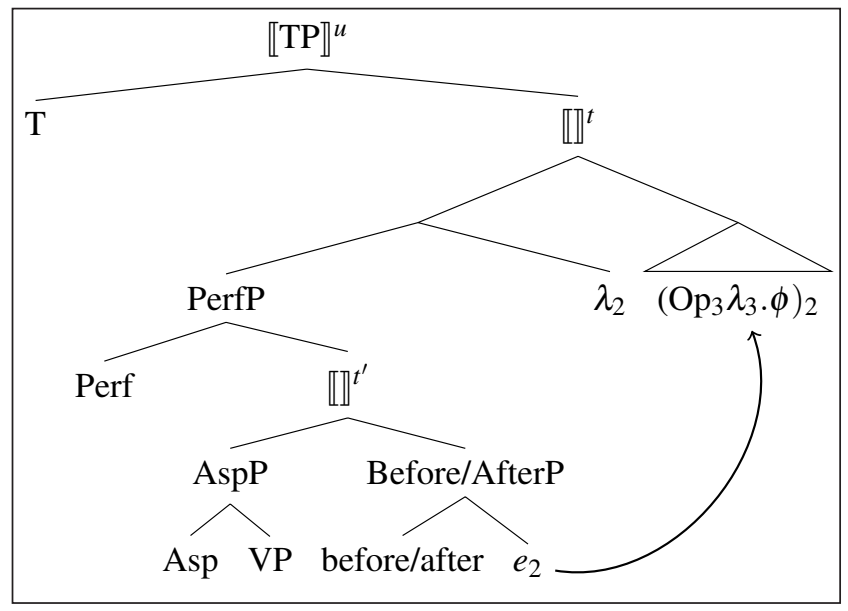

Firstly, like since, inferences associated with the complements of before/after pass canonical presupposition projection tests and are infelicitous when uniqueness is not met. ${ }^{6}$ This is expected if temporal adjunct clauses are generally relative clauses whose relative operator is a definite article.

(32) a. He didn't get a new pet before/after his cat died. $\rightarrow$ the cat died

b. $\quad$ Did he get a new pet before/after his cat died? $\rightarrow$ the cat died

(33) (weird question to find on a car insurance questionnaire)

Did you have your license for at least 10 years before/after you were convicted of drunk driving?

(Context: Katie has gone to Amsterdam three times.)

Max adopted a cat before/after Katie \# (first) went to Amsterdam.

5 Stump (1985) and Sharvit (2013) had a similar insight that such a condition must be responsible for the contrast in (iia,b). This will become an important part of the proposal in future non-perfect contexts.

(ii) (adapted from Smith 1975: 72; Stump 1985: 145)

a. *Max will adopt a cat after Katie left assertion: Max will adopt a cat $\wedge$ adoption follows departure (entailed by the presupposition that Katie left)

b. Max will adopt a cat after Katie said she would leave. assertion: Max will adopt a cat $\wedge$ adoption follows departure (NOT entailed by the presupposition that Katie said she would leave)

6 Beaver \& Condoravdi (2003) build a notion of uniqueness into the meanings of before/after, and thus argue that (34) does not need an element like first to be felicitous. While I disagree with their judgment of examples like (34), the force of my proposal is compatible with their analysis, so I will largely ignore this difference.
Figure 11 When before/after takes a clause, its complement is quantificational and raises to a higher position. 
That said, the complement of before apparently need not be true in the actual world, which is puzzling on the present account. In (35a), the relative operator supposedly presupposes that there is some unique time at which Mozart finished his Requiem. However, this presupposition is apparently not satisfied because Mozart is asserted to have died before such a relevant time.
Glossa: a journal of

general linguistics

DOI: $10.5334 / \mathrm{gjgl} .1429$

$$
\begin{aligned}
& \text { a. Mozart died before he finished his Requiem. (Beaver \& Condoravdi 2003: 48) } \\
& \rightarrow \neg \text { Mozart finished his Requiem. } \\
& \text { b. The police defused the bomb before it exploded. } \\
& \rightarrow \neg \text { The bomb exploded. }
\end{aligned}
$$

These uses of before have been called counterfactual (e.g. Heinämäki 1974; Ogihara 1995) in the sense that the complement of before must be something that would have happened were it not for the matrix event. The complement of before cannot introduce just any false proposition.

$$
\text { \#Mozart died before the Spaghetti Monster took over the Earth. }
$$

Beaver \& Condoravdi (2003) explain this feature of before, while keeping it within the purview of our treatment of after and since, by appealing to the future-referring nature of before. The worlds in which the adjunct event happens are future versions of the worlds in which the matrix event happens. The worlds of evaluation for the complement of before therefore need not be the actual world, but need to share a common history with the actual world up to a certain point.

Following Thomason (1984), they fix for every time $t$ an equivalence relation $\simeq_{t}$ on the set of worlds. On this notion of equivalence, if $w \simeq_{t} w^{\prime}$ and $t^{\prime}<t, w \simeq_{t^{\prime}} w^{\prime}$, which means that for all $t^{\prime}<$ $t, w$ and $w^{\prime}$ are indistinguishable. All worlds $w^{\prime}$ such that $w \simeq_{t} w^{\prime}$ are called historical alternatives of $w$ relative to time $t$, which are proposed to satisfy the following conditions.

Beaver \& Condoravdi (2003: 50)

Initial branch point condition: $\operatorname{alt}(w, t) \subseteq\left\{w^{\prime} \mid w \simeq_{t} w^{\prime}\right\}$

Normality condition: alt $(w, t)$ contains only those historical alternatives of $w$ at $t$ which are reasonably probable given the course of events up to $t$.

Assuming that the adjunct clause has access to these alternative worlds of evaluation, the presupposition in (35a) is satisfied as long as Mozart finished his requiem in one of those worlds. The meaning of before then requires Mozart's death to precede any such time at which he would otherwise have finished his requiem. ${ }^{7}$

So far, I have proposed that past complement clauses of temporal connectives must move to some higher position than their base adjunction positions. We will now investigate the possible base adjunction positions of these adjuncts and the predicted meanings associated with them. The findings of this investigation will be used to predict the full typology of adjunct tenses in perfect and non-perfect contexts.

\subsection{THE SYNTAX OF TEMPORAL CONNECTIVES}

In this section, we observe that since adjuncts only have one adjunction position, namely the one in Figure 10, while before/after have at least two. Section 4 shows how these different base adjunction positions, combined with the requirement that complements of before/after/since must QR, make different predictions for each temporal connective regarding the availability of adjunct past in matrix future perfect and non-perfect contexts.

In prose, since means that its complement demarcates the left boundary of its evaluation time, while before/after order their complements with respect to their evaluation time. Though these

\footnotetext{
7 It's not immediately clear to me how this modality should be formally implemented into the theory. Beaver $\&$ Condoravdi (2003) propose a modal operator earliest, which they propose to be a part of the meanings of before/after. This particular implementation would not explain counterfactual before on my proposal because complements of before/after are proposed to be interpreted outside the scope of the earliest operator. I therefore leave it as a topic for future research to find the right formulation of counterfactual before. As an aside, whether earliest serves another function in the meanings of before/after is also an interesting domain for future research, but is orthogonal to the central claims of this paper. In particular, I have only considered adjunct predicates that are eventive so the trace of the relative clause is always a point. However, if we were to consider stative or imperfective adjunct predicates, the presence or absence of earliest makes particular predictions about the types of overlap that can occur between the adjunct and matrix event times that should be investigated in greater detail.
} 
meanings don't contain any intrinsic constraints on what sorts of intervals they can refer to, there are empirical differences in the distribution of these different adverbials.

In particular, before/after clauses appear to be ambiguous in English in a way that since clauses are not. While before/after clauses can appear in any tensed clause, since clauses appear to only modify the perfect. This is evidenced by the fact that English since cannot modify a clause that does not contain the perfect.

a. They have known each other since 1990.

b. *They knew each other since 1990.

I therefore follow McCoard (1978), Dowty (1979), Iatridou et al. (2001) and many others in referring to since as a perfect-level adverbial (Iatridou et al. (2001)'s term). In our terms, perfect-level modification means adjunction within the immediate scope of the perfect. It may be a unique property of English since that it is an exclusively perfect-level modifier. Conversely, before/after can be both perfect-level and what Iatridou et al. (2001) call eventuality-level modifiers. Here, eventualitylevel modification means adjunction to VP within the immediate scope of aspect (Figure 12).

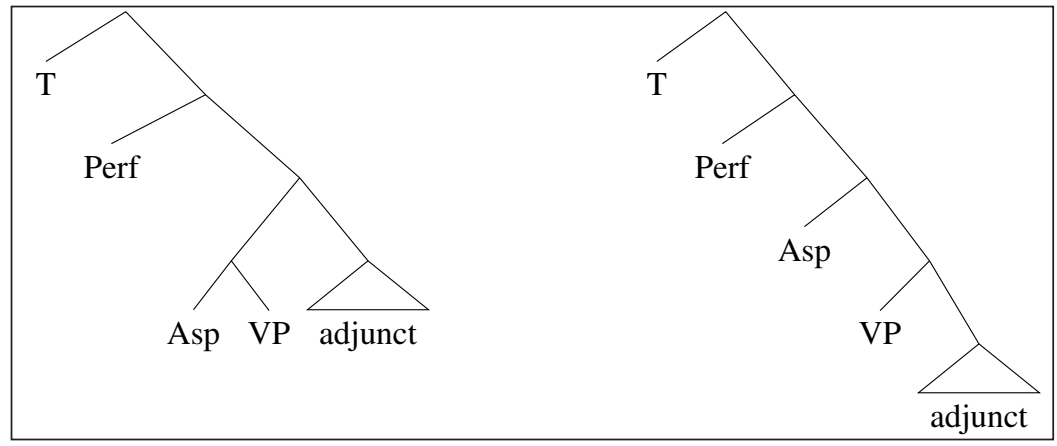

We know that eventuality-level modification is possible for before/after because these adjuncts can modify non-perfects. ${ }^{8}$ We can additionally show, with the help of adverb stacking, that in the presence of a matrix perfect, there is real attachment ambiguity for these adjuncts.

Iatridou et al. (2001), following observations by Dowty (1979) and Vlach (1993), show that for-adverbials can be a useful diagnostic for adjunction position given that their meaning is heavily influenced by word order. While a postverbal for clause can be either a perfect-level or eventuality-level modifier, a pre-posed for clause can only be a perfect level modifier. This is demonstrated in (39). The addition of the adverb never forces an interpretation in which the perfect time span is bounded on the right by the utterance time and extends backwards throughout the speaker's entire life. The modifier for 5 days does not contradict this interpretation if it modifies the matrix eventuality, but it is contradictory if it modifies the perfect time span.

$$
\text { a. I have never ridden a bicycle for } 5 \text { days. }
$$

b. \#For 5 days, I have never ridden a bicycle.

Stacking a before clause on a clause with a pre-posed for adverbial shows that a perfect-level reading is available to before clauses as well.

(40) For 5 days, the British had been fighting before reinforcements arrived. They helped end the fight.

$\underbrace{\text { interval of fighting }}_{\text {perfect time span }=5 \text { days }}$

:ossa: a journal of

general linguistics

DOI: $10.5334 / \mathrm{gjgl} .1429$

Figure 12 Perfect-level vs. eventuality-level modification.
Figure 13 Schematic for interpretation of (40). 
Because the example in (40) has a U-perfect, the period of fighting may be longer than the perfect time span (Figure 13). The for adverbial dictates the duration of the perfect time span but not necessarily the duration of the battle. There is an interpretation of (40) in which the before clause introduces a time after the 5-day period but before the battle ends. This interpretation suggests that the before clause adjoins just below the perfect, ordering the adjunct event with respect to the perfect time span, not the event time.

This is not only a possible interpretation of (40), but also the most natural one. Following (40) with (41) makes the speaker sound extremely unhelpful. If the Brits' arrival was understood to follow the battle rather than the perfect time span, (41) should be a reasonable utterance in the context of (40).

$$
\text { \#...they arrived a week after the fighting began. }
$$

Changing the U-perfect to an E-perfect, however, reveals an eventuality-level interpretation for the before clause. In (42), there is an interval of 5 days in which the Americans move their camp before the arrival of the British (and ambush them), which comes about if the before clause attaches to VP rather than aspect.

During the last 5 days of August, the Americans had moved their camp before the British arrived, and ambushed them from the other side.

We therefore have evidence that before can be either a perfect-level or eventuality-level modifier. However, while it is easy to see that after can also have an eventuality-level interpretation (shown in (43)), it is less straightforward to show that it can have a distinct perfect-level interpretation.

During the last 5 days of August, the Americans had beaten the British after moving their camp, and ended the war.

Trying to make (43) a U-perfect along the lines of (40) will not distinguish the adjunction position of the after clause. This is because it is very difficult, if not impossible, to construct a scenario in which the adjunct event precedes the perfect time span but not the eventuality. The counterpart to (40), as in (44), could be ambiguous between a perfect-level and an eventualitylevel interpretation with no consequences for the meaning (Figure 14).

For 5 days, the Americans had been fighting after the British arrived. The British started the fight.

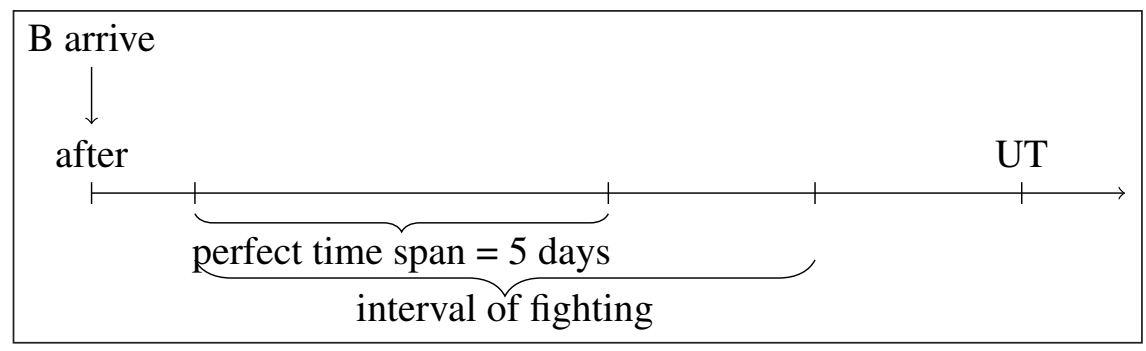

We will see that whether after can have a perfect-level interpretation ultimately does not affect the predictions of the theory. I will discuss the predictions for adjunct tense on the conservative assumption that before/after can be either perfect-level or eventuality-level modifiers. We will see, however, that only some adjunction distinctions are crucial.

To summarize, since clauses are unambiguously perfect-level modifiers. Past clausal complements of since cannot be interpreted in situ, so they must QR to a position where they can be interpreted, namely just below T. We will now investigate the predictions for before/after clauses on the assumption that they can be either perfect-level or eventuality-level modifiers. The base adjunction position of before/after clauses will affect whether there is a higher position that their clausal complements can move to and what the adjunct tense possibilities are for that position. We begin by looking at the places in the clausal spine where adjunct past is predicted to be meaningful.
Glossa: a journal of

general linguistics

DOI: $10.5334 / \mathrm{gjgl} .1429$
Figure 14 Schematic for interpretation of (44). 


\section{PREDICTING THE DISTRIBUTION OF ADJUNCT PAST}

We will now investigate the predicted distribution of adjunct past in future perfect contexts, given the different base adjunction positions of before/after clauses. We will see that adjunct past is always predicted to be available for eventuality-level adjuncts because there is a QR landing site below tense that results in a meaningful interpretation of an adjunct past. By contrast, adjunct past is not uniformly available to perfect-level adjuncts: adjunct past is predicted to be licensed for after but not before clauses.

\subsection{BEFORE}

Recalling the examples in (15), before is compatible with both adjunct past and present in future perfect contexts. We have also seen that before clauses are ambiguously eventualitylevel or perfect-level modifiers. Here we see that only eventuality-level modification is predicted to license an adjunct past in before clauses, and this adjunct past is predicted to be interpreted relative to the output of matrix tense. Perfect-level before clauses have a meaning that contradicts an adjunct past interpreted anywhere.

If all goes according to plan, by the time she is 30 , Katie will have gotten her PhD before her brother did/does/has.

An eventuality-level before clause in (15) would order Katie's PhD (matrix event) before her brother's (adjunct event). This is schematized in the timeline on the right in Figure 15. The tree on the left in Figure 15 represents the only LF that licenses an adjunct past tense given the base adjunction position of the before clause.

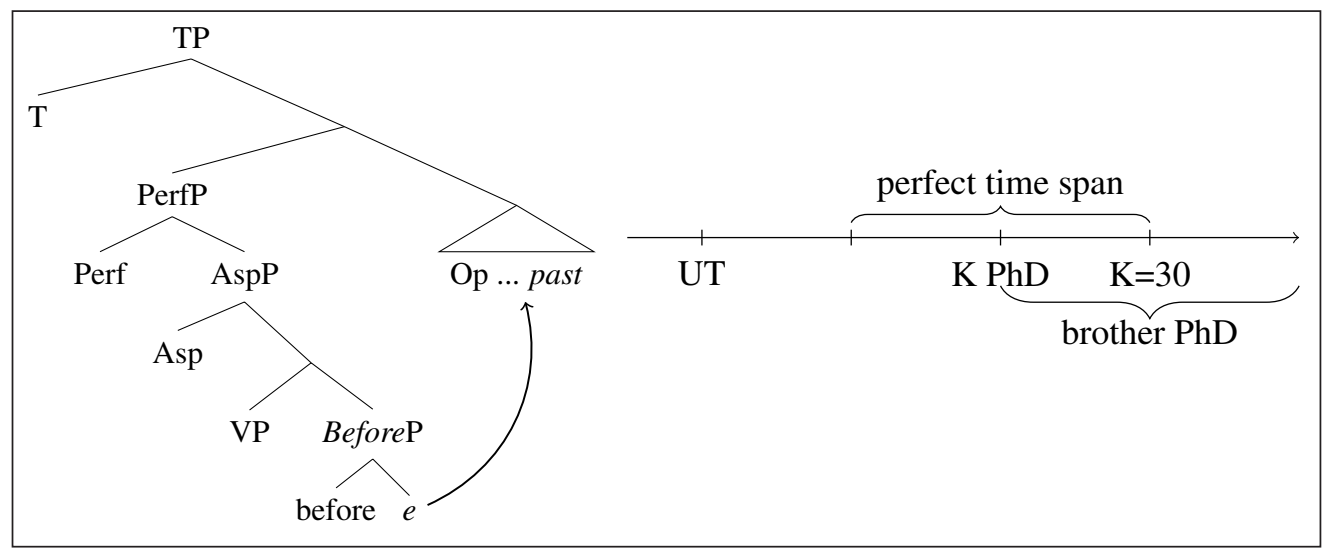

As we saw in Section 3.1, a past tense inside the before clause results in a contradiction if interpreted in situ: a past tense interpreted in situ would situate Katie's brother's PhD before hers, which is the exact opposite of the meaning of before. Inspecting the timeline in Figure 15, we also see that the contradiction is not resolved if the adjunct past is interpreted with respect to either the entire perfect time span, or UT. However, if it is interpreted with respect to the right boundary of the perfect time span (i.e. Katie's 30th birthday), there is no contradiction. It is perfectly possible for Katie's brother to get his PhD after Katie gets hers but before she turns 30. Thus, an adjunct past can be interpreted with respect to the output of tense, but no other time. According to the predictions of the theory, this result corresponds to a derivation in which the complement of before raises to a position within the scope of woll.

If we consider a higher adjunction position for the before clause, i.e. perfect-level adjunction, Katie's brother's PhD should now be ordered with respect to the perfect time span that contains Katie's PhD, rather than the event time. This state of affairs is contradicted by an adjunct past interpreted anywhere. Katie's brother's PhD cannot be past with respect to the right boundary of the perfect time span, while strictly following the perfect time span (Figure 16).

To summarize, a relative adjunct past is licensed for eventuality-level but not perfectlevel before clauses. We will now demonstrate the predicted distribution of adjunct past in after clauses.
Figure 15 Eventuality-level before: adjunct past licensed if the adjunct clause raises to just below $T$. 


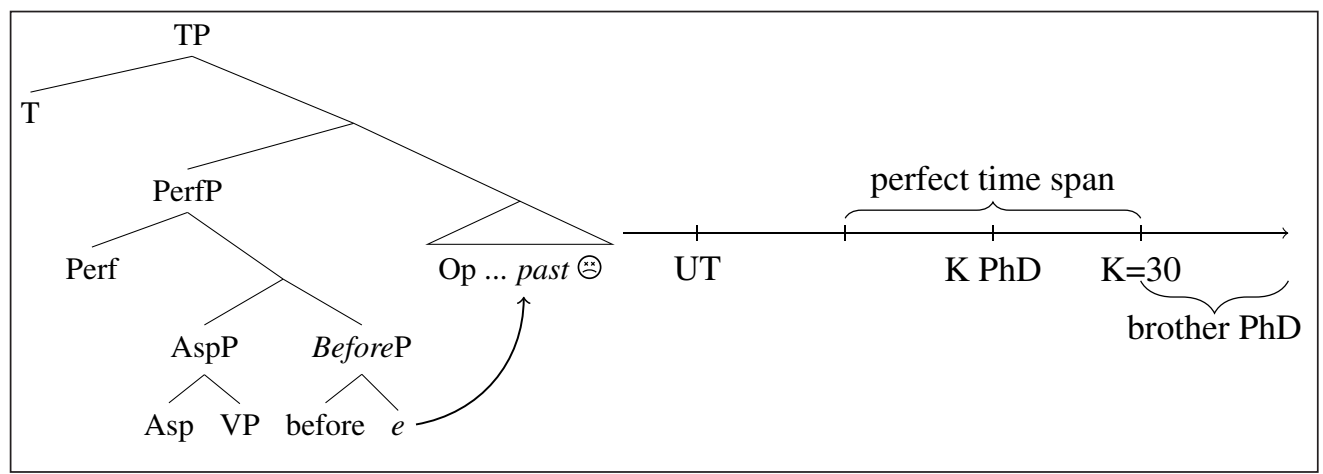

\subsection{AFTER}

As we saw for before, if an after clause is an eventuality-level modifier, an adjunct past is predicted to be licensed, and must be interpreted relative to the right boundary of the perfect time span. The meanings of after clauses demand that Katie's brother's PhD precede Katie's, which is in principle satisfied by an adjunct past interpreted anywhere (see the timeline in Figure 17). However, only an adjunct past interpreted just below tense satisfies the pragmatic condition in (30); all other possibilities are redundant.

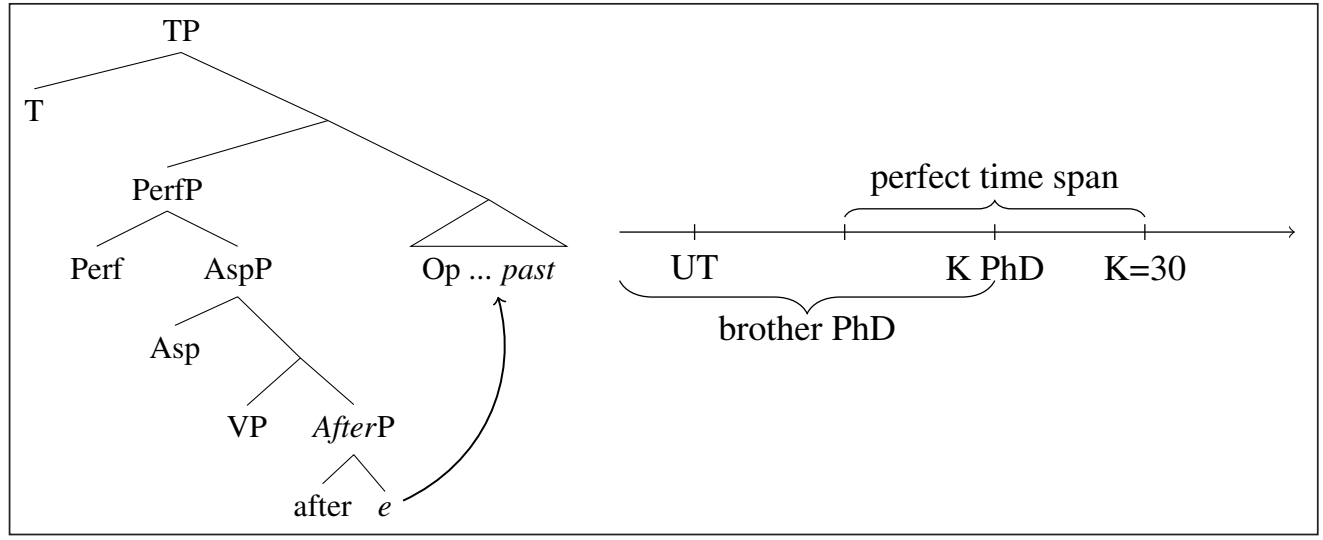

(15) If all goes according to plan, by the time she is 30 , Katie will have gotten her PhD after her brother did/??does.

a. If adjunct past is interpreted within the scope of the perfect, or outside the scope of tense

i. presupposition: Katie's brother's PhD is past w.r.t. Katie's PhD, the perfect time span that contains it, or UT

ii. assertion: Katie will have gotten a PhD by the time she is 30 .

iii. assertion: Katie's brother's PhD will precede hers. (redundant given the presupposition in (i))

b. If adjunct past is interpreted above the perfect but below woll

i. presupposition: Katie's brother PhD is past w.r.t. the right boundary of the perfect time span

ii. assertion: Katie will have gotten a PhD by the time she is 30 .

iii. assertion: Katie's brother's PhD will precede hers. (NOT redundant given the presupposition in (i))

Unlike before, however, an adjunct past is also licensed if the after clause adjoins as a perfectlevel modifier (schematized in Figure 18). The condition in (30) rules out an adjunct past interpreted in situ, but not in a position just below matrix tense.

(15) If all goes according to plan, by the time she is 30 , Katie will have gotten her PhD after her brother did/??does.

a. If adjunct past is interpreted above the perfect but below woll

i. presupposition: Katie's brother $\mathrm{PhD}$ is past w.r.t. the right boundary of the perfect time span.
Figure 16 Perfect-level before: adjunct past is not licensed.

Figure 17 Eventuality-level after: adjunct past licensed if the adjunct clause raises to just below $\mathrm{T}$. 


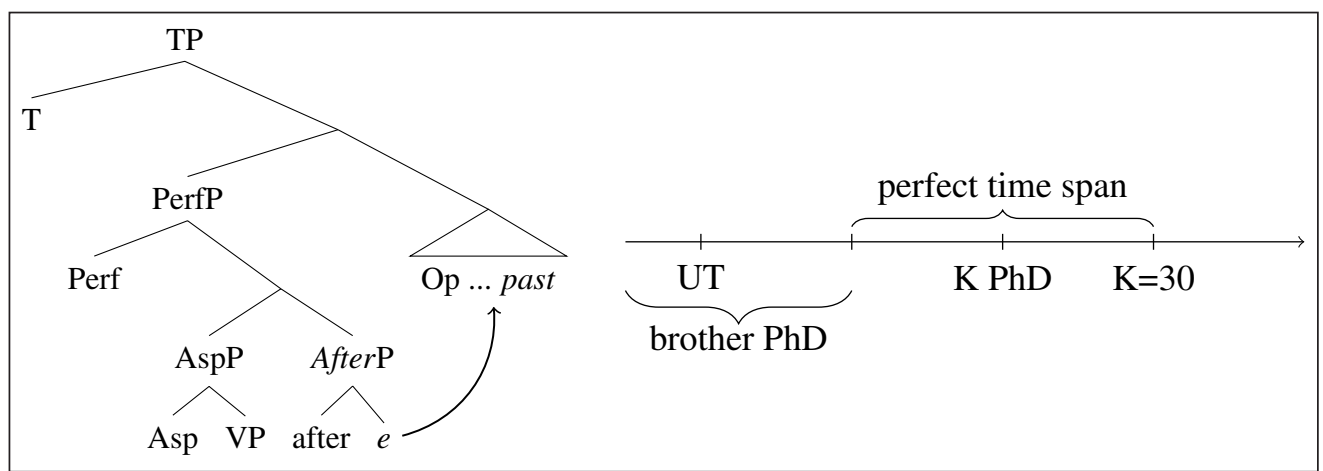

ii. assertion: Katie will have gotten a PhD by the time she is 30 .

iii. assertion: Katie's brother's PhD will precede the perfect time span in which Katie gets her PhD. (NOT redundant given the presupposition in (i))

We could also test for the availability of adjunct past in before/after clauses if they adjoined even higher, i.e. as tense-level modifiers. It is not obvious that before/after clauses ever adjoin that high, but if they did, no adjunct past would be licensed because the nearest QR position is outside the scope of matrix tense. Adjunct past would therefore have to be interpreted with respect to UT, which is contradictory for before clauses and redundant for after clauses.

In summary, adjunct past is licensed for some but not all adjunction positions of before/after clauses. Adjunct past is always licensed in eventuality-level before/after clauses, but never tense-level ones (a hypothetical but not empirically motivated possibility). Perfect-level before/ after clauses show non-uniform behavior for adjunct past: adjunct past is licensed for perfectlevel after clauses because being past with respect to the perfect time span is not entailed by being past relative to its right boundary. However, adjunct past is not licensed for perfect-level before clauses because a single time cannot both follow the perfect time span while preceding its right boundary.

The predicted distribution of adjunct past in matrix future perfect contexts is summarized in Table 1 (for a complete list of computations, see Appendix). Combinations of base adjunction position and QR landing site that allow adjunct past are marked with $\checkmark$. Combinations that disallow adjunct past are marked with either ${ }^{*} \mathrm{C}$ or ${ }^{*} r$ depending on whether they are ruled out due to a contradiction or a redundancy.

\begin{tabular}{llllll}
\hline & ADJ. SITE $\downarrow /$ QR SITE $\rightarrow$ & VP & ASPP & PERFP & TP \\
\hline Before & eventuality-level & ${ }^{*} \mathrm{C}$ & ${ }^{*} \mathrm{C}$ & $\checkmark$ & ${ }^{*} \mathrm{C}$ \\
\hline & perfect-level & - & ${ }^{*} \mathrm{C}$ & ${ }^{*} \mathrm{C}$ & ${ }^{*} \mathrm{C}$ \\
\hline tense-level & - & - & ${ }^{*} \mathrm{C}$ & ${ }^{*} \mathrm{C}$ \\
\hline \multirow{2}{*}{ After } & eventuality-level & ${ }^{*} r$ & ${ }^{*} r$ & $\checkmark$ & ${ }^{*} r$ \\
\hline & perfect-level & - & ${ }^{*} r$ & $\checkmark$ & ${ }^{*} r$ \\
\hline & tense-level & - & - & ${ }^{*} r$ & ${ }^{*} r$ \\
\hline
\end{tabular}

This approach therefore corroborates the intuition from Section 1 that the presence of the perfect in a sentence licenses relative adjunct past. We will now see that this relative past is normally ruled out in future non-perfect contexts.

\subsection{BACK TO THE FUTURE NON-PERFECT}

In the absence of the perfect, there is no perfect-level adjunction, so our domain of investigation only includes eventuality-level and tense-level adjunction sites. We have already shown that tense-level adjunction rules out a relative adjunct past: interpreting an in situ adjunct past is always contradictory or redundant, as is interpreting it relative to the time of utterance (the only available QR position). We now observe that in the absence of the perfect, the meanings of eventuality-level vs. tense-level before/after clauses are essentially indistinguishable, thus predicting a lack of adjunct past for eventuality-level before/after clauses as well.
Figure 18 Perfect-level after: adjunct past licensed if the adjunct clause raises to just below $\mathrm{T}$.

Table 1 The predicted distribution of adjunct past in before/after clauses for various adjunction positions and QR sites in future perfect contexts. 
An adjunct past in a before clause is contradictory no matter where it is interpreted in Figure 19: Katie's departure cannot be past with respect to the adoption, the woll time containing it or UT without contradicting the meaning of before. This prediction corresponds to the observation that adjunct past is ruled out in before clauses in future non-perfect contexts.
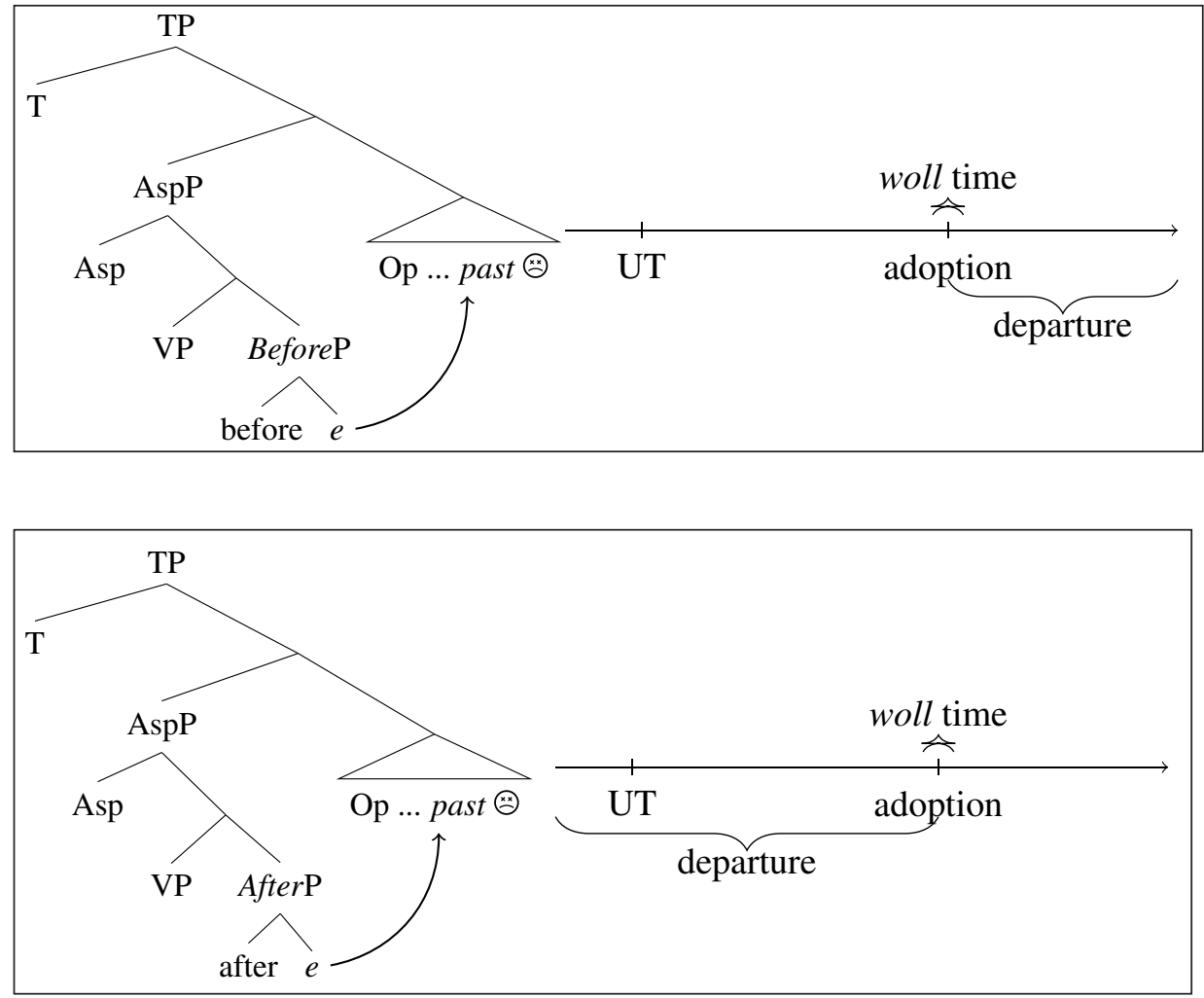

(45)

*I will adopt a cat before Katie left.

Likewise, an adjunct past in an after clause is always ruled out by redundancy (see Figure 20). Whether an adjunct past is interpreted in situ, below woll, or outside the scope of tense, it violates the condition on redundancy. This corresponds to the observed lack of adjunct past in (46).

(46) *I will adopt a cat after Katie left.

Table 2 summarizes where an adjunct past is predicted to be licensed given different combinations of adjunction position and QR site. It shows that there are no combinations in which an adjunct past is licensed, thus correctly accounting for the absence of adjunct past in these future non-perfect contexts. As in Table 1, combinations that disallow adjunct past are marked with either ${ }^{*} \mathrm{C}$ or ${ }^{*} \mathrm{r}$ depending on whether they are ruled out due to a contradiction or a redundancy.

\begin{tabular}{lllll}
\hline & ADJ. SITE $\downarrow /$ QR SITE $\rightarrow$ & VP & ASPP & TP \\
\hline Before & eventuality-level & ${ }^{{ }^{*} \mathrm{C}}$ & ${ }^{{ }^{*} \mathrm{C}}$ & ${ }^{{ }^{*} \mathrm{C}}$ \\
\hline \multirow{2}{*}{ After } & tense-level & - & ${ }^{{ }^{*} \mathrm{C}}$ & ${ }^{{ }^{*} \mathrm{C}}$ \\
\hline \multirow{2}{*}{ eventuality-level } & ${ }^{{ }^{*} \mathrm{r}}$ & ${ }^{{ }^{*} \mathrm{r}}$ & ${ }^{{ }^{*} \mathrm{r}}$ \\
\hline & tense-level & - & ${ }^{{ }} \mathrm{r}$ & ${ }^{{ }^{*} \mathrm{r}}$ \\
\hline
\end{tabular}

We have seen that this system correctly rules out relative past in (45) and (46) and rules in relative past in future perfects. Now we turn our attention to the other side of the problem, which pertains to the distribution of adjunct present tense morphology in future contexts.

What is important to note here is that all of the examples so far contain eventive predicates, which normally reject the English simple present. Assuming that the conditions regulating matrix present tense are active in adjunct clauses as well, the adjunct present morphology observed in (2) is never predicted. However, there are a number of scenarios in which an adjunct lossa: a journal of

general linguistics

DOI: $10.5334 / \mathrm{gjgl} .1429$

Figure 19 Eventuality-level before: no adjunct past.

Figure 20 Eventuality-level after: no adjunct past.
Table 2 The predicted distribution of adjunct past in before/after clauses for various adjunction positions and QR sites in future non-perfect contexts 
future is predicted to be licensed. Section 5 shows that all of the scenarios in which adjunct future is predicted correspond to places where adjunct present is observed. I will therefore propose, following McCawley (1971), Comrie (1982) and Dancygier (1998), that adjunct future involves woll-deletion, stranding bare present morphology.

\section{ADJUNCT PRESENT}

The appearance of adjunct present in (2) is surprising because it has different properties than the regular English present. Matrix and embedded present is normally restricted to predicates with the subinterval property, or else it induces habitual or generic readings. However, adjunct present appears on non-statives and non-progressives, and does not correspond to a habitual or generic reading. English present also typically has a simultaneous interpretation, but the adjunct events are not necessarily interpreted as contemporaneous with UT or any other salient time. Adjunct present likewise does not show the properties of English futurate present, which requires a "plan" reading (Dowty 1979; Copley 2008; Kaufmann 2005).

I propose to relate this puzzle to another one, which has eluded every analysis of English adjunct tense that I know of, namely the absence of adjunct future in any context. Adjunct clauses appear to be a context in which English present and future are in complementary distribution.

${ }^{*}$ I will adopt a cat before/after/when Katie will leave.

The adjunct present in examples like (2) behaves like a future in nearly every respect. It does not discriminate on the basis of aktionsart, it doesn't require a "plan" reading or a generic interpretation, and it introduces a time that is understood to follow UT. It is therefore conceivable that the LF that corresponds to adjunct present in (2) contains an adjunct woll + pres rather than a simple present operator. On this analysis, adjunct present in (2) is the output of an English-specific pronunciation rule that deletes adjunct instances of woll.

This proposal is based on analyses of English adjunct present morphology in conditionals. As Wekker (1977) and others discuss, temporal adverbial clauses appear to be part of a class of subordinative constructions in which woll is systematically unavailable. The addition of woll in a conditional clause is ill-formed unless there is an available reading with volitionality or inevitability. This extra reading is proposed to be unavailable to temporal adverbial clauses, thus accounting for the complete lack of woll in those contexts.

a. If Max is left destitute, I'll change my will.

Uncertainty about whether Max will be left destitute. I will decide whether to change my will if/when such destitution is realized.

b. If Max will be left destitute, I'll change my will.

Relevant knowledge about Max's future destitution is available now, so my decision to change my will is in the immediate future.

(Wekker 1977: 66)

On the basis of minimal pairs like $(48 a, b)$, it has been argued that examples without woll, like (48a), have an underlying representation like that of (48b). The example is ultimately pronounced in (48a), however, due to a woll-deletion rule that applies unless woll contributes an additional reading beyond simple future reference (McCawley 1971; Comrie 1982; Dancygier 1998). I will assume a version of this pronunciation rule for temporal adverbial clauses as well (illustrated in Figure 21).

Sharvit (2013), following Ogihara (1996), notes that there are a few exceptions to this rule, such as under ellipsis.

$$
\text { Max will leave before Katie will. (Sharvit 2013: 24, fn. 10) }
$$

The availability of adjunct woll in a prosodically special context, such as ellipsis, corroborates the view that the lack of adjunct future is an effect of pronunciation rather than the semantics.

If we take for granted that adjunct present has the profile of a future tense, we can predict its distribution with the same reasoning that we used to predict the distribution of adjunct past. What we find is that adjunct future is always redundant or contradictory, except when it outscopes matrix tense. This result cross-cuts the perfect/non-perfect distinction in the matrix clause. 


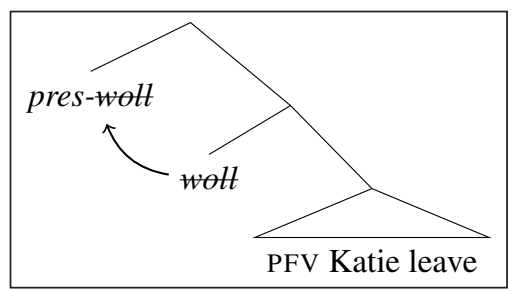

Starting with matrix future perfects, we can check each adjunction position of before/after clauses and subsequent QR sites for the availability of adjunct future. For after clauses, adjunct future is contradictory unless it is interpreted with respect to UT. This is true regardless of where the after clause adjoins (Figure 22).

$\underbrace{\mathrm{UT}_{\text {brother PhD (p-level) }}^{\text {K PhD }}}_{\text {brother PhD (e-level) }}$

Similarly, adjunct future in a before clause is always redundant unless it is interpreted with respect to UT (Figure 23).

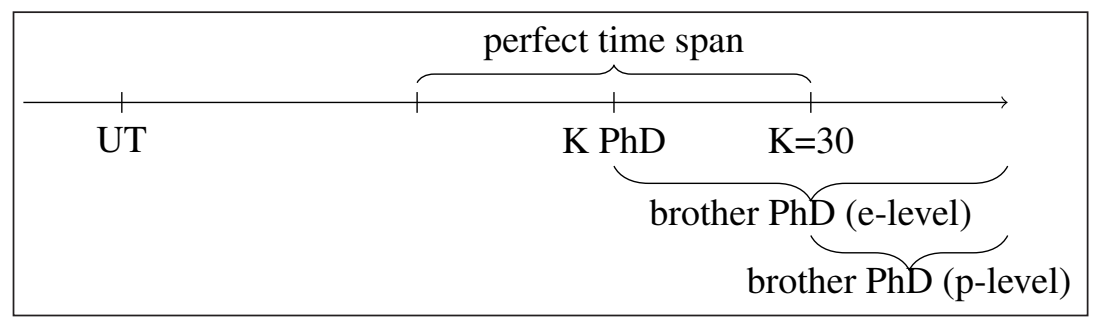

(50) By the time she is 30, Katie will have gotten her PhD before her brother does ${ }^{k P h D, k=30}$.

a. presupposition: Katie's brother's PhD is future w.r.t. her PhD or the interval that contains it.

b. assertion: Katie will get a PhD.

c. assertion: Katie's PhD precedes her brother's. (redundant given (a))

(51) By the time she is 30, Katie will have gotten her PhD before her brother does ${ }^{\mathrm{UT}}$.

a. presupposition: Katie's brother's PhD is future w.r.t. UT.

b. assertion: Katie will get a PhD.

c. assertion: Katie's PhD precedes her brother's. (NOT redundant given (a))

In summary, adjunct future is only licensed if it is interpreted very high, outside the scope of any matrix temporal operators. This result is summarized in Table 3, which shows the full space of adjunction and QR positions (for a complete list of computations, see Appendix).

\begin{tabular}{llllll}
\hline & ADJ. SITE $\downarrow /$ QR SITE $\rightarrow$ & VP & ASPP & PERFP & TP \\
\hline Before & eventuality-level & ${ }^{*} r$ & ${ }^{*} r$ & ${ }^{*} r$ & $\checkmark$ \\
\hline & perfect-level & - & ${ }^{*} r$ & ${ }^{*} r$ & $\checkmark$ \\
\hline tense-level & - & - & ${ }^{*} r$ & $\checkmark$ \\
\hline After & eventuality-level & ${ }^{*} \mathrm{C}$ & ${ }^{*} \mathrm{C}$ & ${ }^{*} \mathrm{C}$ & $\checkmark$ \\
\hline & perfect-level & - & ${ }^{*} \mathrm{C}$ & ${ }^{*} \mathrm{C}$ & $\checkmark$ \\
\hline & tense-level & - & - & ${ }^{*} \mathrm{C}$ & $\checkmark$ \\
\hline
\end{tabular}

Glossa: a journal of

general linguistics

DOI: $10.5334 / \mathrm{gjgl} .1429$

Figure 21 The future modal woll, which normally composes morphologically with tense, is deleted in subordinate contexts.

Figure 22 Whether after is an eventuality-level or a perfect-level modifier, adjunct future is contradictory unless interpreted w.r.t. UT.

Figure 23 Whether before is an eventuality-level or a perfect-level modifier, adjunct future is redundant unless interpreted w.r.t. UT.

Table 3 A summary of adjunct future licensing in before/ after clauses in matrix future perfect contexts $\left({ }^{*} \mathrm{C}={ }^{*}\right.$ due to contradiction; ${ }^{*} r={ }^{*}$ due to redundancy) 
By the same logic, removing the perfect from the matrix clause results in the same predicted distribution of adjunct future. In future non-perfect contexts, adjunct future is only licensed if it outscopes matrix tense (Table 4).

\begin{tabular}{lllll}
\hline & ADJ. SITE $\downarrow /$ QR SITE $\rightarrow$ & VP & ASPP & TP \\
\hline Before & eventuality-level & ${ }^{{ }_{r}}$ & ${ }^{{ }_{r}}$ & $\checkmark$ \\
\hline \multirow{2}{*}{ After } & tense-level & - & ${ }^{{ }^{*}}$ & $\checkmark$ \\
\hline \multirow{2}{*}{ eventuality-level } & ${ }^{*} \mathrm{C}$ & ${ }^{{ }^{*} \mathrm{C}}$ & $\checkmark$ \\
\hline & tense-level & - & ${ }^{*} \mathrm{C}$ & $\checkmark$ \\
\hline
\end{tabular}

We can now combine these results with the predicted distribution of adjunct past. In future non-perfect contexts, adjunct past was predicted never to be licensed, while adjunct future was predicted to be licensed if the adjunct clause outscopes matrix tense. The theory therefore correctly predicts uniformity in future non-perfect contexts: we should always expect adjunct future in examples like (2), where the future is interpreted with respect to UT. I propose that we observe uniform present morphology in the adjunct clauses instead of uniform future tense due to a pronunciation rule that deletes woll in these contexts.

In future perfect contexts, however, adjunct future is not the only option. Some adjunction positions and temporal connectives license adjunct past as well. Adjunct past is always licensed in a position lower than adjunct future. I therefore propose that locality constrains the system, so the first viable QR site is the locus of adjunct tense interpretation. This predicts that scenarios in which an adjunct past is licensed always realize adjunct past, because there is no need to QR to a higher position.

This prediction is borne out by since clauses, which uniformly reject adjunct present nonperfect. Since clauses behave this way because the closest viable QR site licenses an adjunct past or a present perfect, but not a future. The predictions for before/after are shown in Table 5.

\begin{tabular}{lll}
\hline & ADJ. SITE & PREDICTED ADJUNCT TENSE \\
\hline Before & e-level & past \\
\hline & p-level & future \\
\hline & t-level & future \\
\hline After & e-level & past \\
\hline & p-level & past \\
\hline & t-level & future \\
\hline
\end{tabular}

If we assume that every instance of adjunct future is pronounced as a present tense, this analysis correctly predicts optionality between past/present for before clauses but not for after clauses (unless the after clause is used as a tense-level modifier, which is currently only a hypothetically possible reading). This is because the two diagnosable adjunction positions for before/after clauses correspond to different outcomes for the complement of before but not for after.

Generalizing these results, we expect the availability of a relative adjunct past to be insensitive to the value of matrix tense. Whether the matrix perfect is in the future or in the past does not affect whether the adjunct event can be past relative to the output of tense. Only when the adjunct tense is interpreted with respect to the time of utterance do we expect adjunct tense to be sensitive to the value of matrix tense. If the matrix event time is in the past, an adjunct future will always be contradictory or redundant, but an adjunct past is always licensed; the opposite is true for matrix future.

\subsection{WHEN}

Until now, I have put aside a demonstration of the predictions this theory makes for when clauses. This is because the meaning of when is less clear. Moens \& Steedman (1988) show ssa: a journal of

general linguistics

DOI: $10.5334 / \mathrm{gjgl} .1429$

Table 4 A summary of adjunct future licensing in before/after clauses in matrix future nonperfect contexts

Table 5 Predicted adjunct tense for each adjunction position in future perfect contexts 
that when is compatible with a number of interpretations. In (52), the three different matrix clauses indicate a different temporal ordering between the when clause and the matrix event.

(52) When they built the 39th Street bridge... (Moens \& Steedman 1988: 23)
a. ...a local architect drew up the plans.
b. $\quad$...they used the best materials.
c. ...they solved most of their traffic problems.

In (52a), the matrix event is understood to precede the adjunct event because planning typically precedes a building project. In (52b), there is coincidence between the two events, and in (52c), the matrix event is understood to follow completion of the adjunct event. These three interpretations do not all follow straightforwardly from a uniform meaning of when, assuming when explicitly orders the adjunct event time with respect to the matrix event time.

A unified meaning of when is not crucial for our present purposes, however. What is important is that the observed tenses in when clauses are compatible with the various possible interpretations in (52). The present analysis has already covered before/after clauses, which could conceivably describe the scenarios in $(52 a, c)$. We will now demonstrate the predictions for a meaning for when that requires coincidence between the matrix and adjunct events. Recall that when clauses allow both past and present in future perfect contexts, but only present in future non-perfect contexts.

(15) If all goes according to plan, by the time she is 30 , Katie will have gotten her PhD when her brother did/?does/has.

To investigate when clauses, we must additionally investigate the possible base adjunction positions of when. In (53), it appears that when can have either an eventuality-level or a tenselevel interpretation, but not a perfect-level one. This is because the adjunct event cannot be understood to be at the entire perfect time span.

For 5 days, I had been riding my bike when Katie arrived.

Eventuality-level reading: Each day for 5 days, I was riding my bike at the time that Katie arrived. (when modifies event time)

Tense-level reading: At the end of a 5-day period of bike riding, Katie arrived. (when modifies right boundary of perfect time span)

Assuming that a when clause with an at interpretation can either adjoin low or high, we can compute the possible adjunct tenses for each. Because the adjunct clause is eventive, a regular present tense is never possible, so we are again looking for adjunct past or future. Notice that neither is licensed in situ because any in-situ tense will contradict a simultaneous interpretation of when.

[when Katie left $]=\left[\right.$ at $\left[\mathrm{Op}_{3}\left[\lambda_{3}\left[\mathrm{PST}\right.\right.\right.$ PFV K leave at $\left.\left.\left.e_{3}\right]\right]\right]$

$\llbracket$ at $\left[\mathrm{Op}_{3}\left[\lambda_{3}\left[\right.\right.\right.$ PST PFV K leave at $\left.\left.\left.e_{3}\right]\right]\right] \rrbracket^{t, g}=1$ iff $\ldots$

a. $\quad t=\llbracket \mathrm{Op}_{3}\left[\lambda_{3}\left[\right.\right.$ PST PFV K leave at $\left.\left.e_{3}\right]\right] \rrbracket^{t, g}=$ the $\tau$ s.t. $\exists t^{\prime}<t$. $\exists t^{\prime \prime} \subseteq t^{\prime}$. K leave at $\tau \wedge \tau=t^{\prime \prime}$

b. Result: $\tau<t$ (contribution of adjunct past) AND $\tau=t$ (contribution of at) contradiction

If adjunct tense were future instead of past:

Result: $\tau>t$ (contribution of adjunct past) AND $\tau=t$ (contribution of at) contradiction

The complement of when must therefore QR to some higher position in any case. In the case of high adjunction, the only place to move is above tense, in which case we expect adjunct future interpreted with respect to UT (pronounced as present). If the when clause adjoins low, and the matrix clause is a future perfect, there is a position below $T$ that the adjunct clause can QR to, which licenses a relative past. We thus correctly predict both adjunct past and present (underlyingly future) to be licensed for when clauses, where each choice corresponds to a different adjunction position (shown in Figures 24 and 25). 

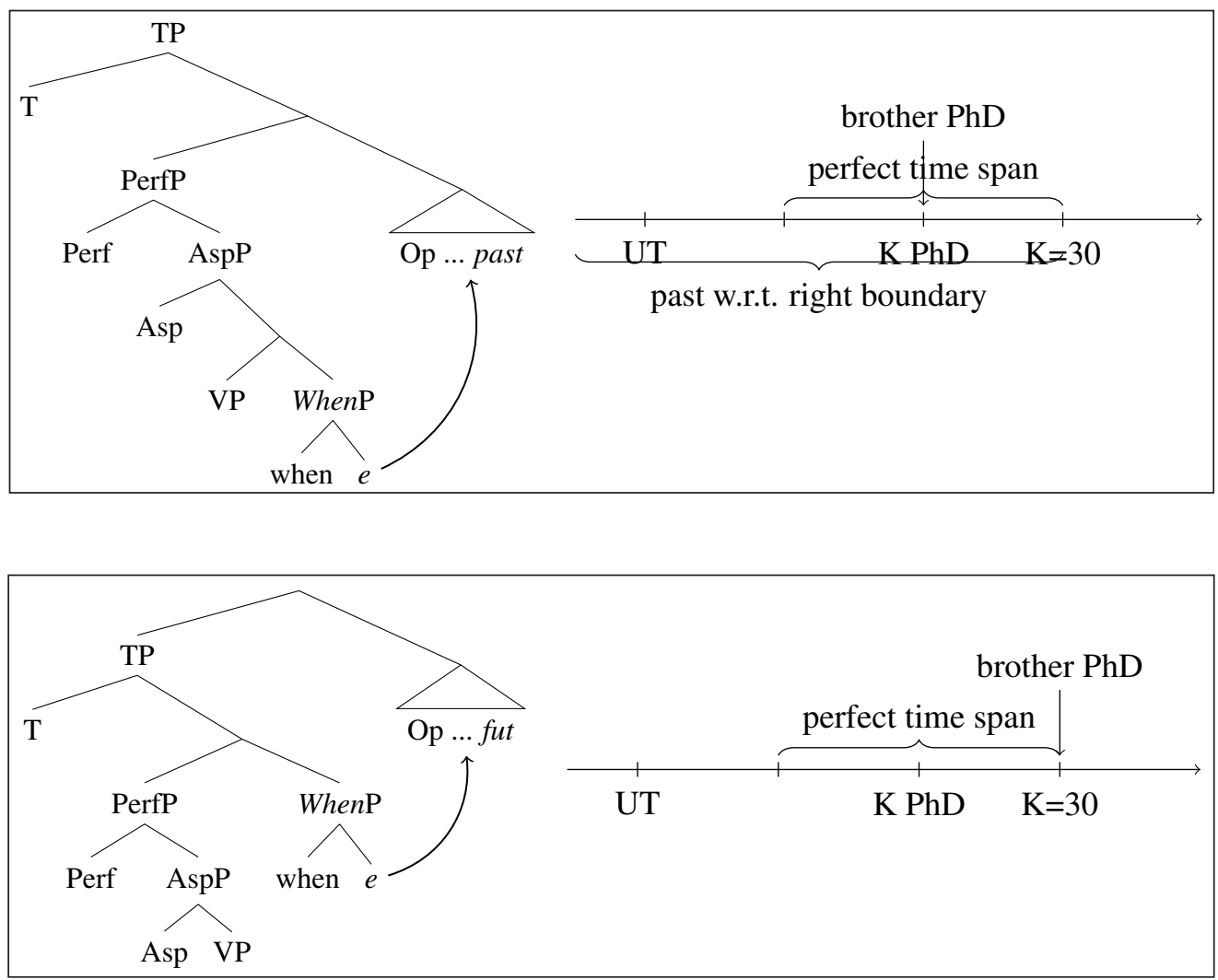

Removing the perfect makes any relative adjunct tense contradictory because the matrix event time is contained in the woll-time. If an adjunct past/future interpreted relative to the event time is contradictory, it will stay contradictory if interpreted relative to the woll-time. Therefore, the only possible adjunct tense is a future evaluated with respect to UT, which is pronounced as a present.

We have seen that a relative adjunct past is correctly predicted to be licensed for before/after/ when/since clauses when the matrix clause is a perfect but not a future non-perfect, and that adjunct present (underlying future) is always predicted to be interpreted with respect to UT. This conclusion stands in contrast with analyses that propose adjunct present morphology to be a Sequence of Tense (SOT) phenomenon. We will now visit analyses of these sort and show why they are less successful than the present approach.

\section{SOT ANALYSES OF ADJUNCT PRESENT}

I have advanced a theory that treats adjunct tenses in English at face value, so to speak. Adjunct past is observed when the adjunct event is interpreted as past with respect to some time. Adjunct future (pronounced as present) is observed when adjunct past is not licensed and the adjunct event is interpreted as future with respect to UT. This stands in contrast with approaches that treat adjunct tenses as vacuous tense morphology, licensed by an SOT mechanism.

SOT describes configurations of subordinate past within the context of a matrix past that are ambiguous between two interpretations. This is demonstrated in (57), which is ambiguous between the so-called backshifted and simultaneous readings. On the backshifted interpretation, the embedded past is interpreted as a "real" past operator and requires the embedded interval to strictly precede Katie's belief time. On the simultaneous reading, the embedded past is interpreted like a relative present tense, which induces overlap between the embedded interval and the belief time.

Katie believed that her cat was angry.

$\underbrace{\mathrm{a} \quad \text { K's belief time UT }}_{\text {cat's angry time }}$

(a) Backshifted reading: $a<b$
Figure 24 Eventuality-level when: licenses adjunct past interpreted just below matrix $T$.

Figure 25 Tense-level when: licenses adjunct future outside the scope of matrix T. 


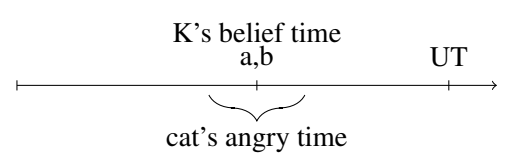

(b) Simultaneous reading: $a \circ b$

The simultaneous interpretation is assumed to correspond to an LF that does not contain a regular embedded past operator. Instead, this LF contains either a vacuous tense or an embedded present (these might be the same thing depending on the theory), but bears past morphology because of a grammatical process that assigns the morphology of the matrix tense to the embedded clause.

Katie believed that her cat was angry.

LF1: [ past Katie believe [ that past her cat be angry ]] (back-shifted reading)

LF2: [ past Katie believe [ that ?? her cat be angry ]] (simultaneous reading)

Assuming that this grammatical process can also transmit matrix tense morphology to adjunct clauses, there is an interpretation of adjunct past in (1) in which the past morphology is not indicative of a past interpretation, but is rather parasitically licensed by the matrix past. By extension, adjunct present might be observed when the matrix tense is future because the English future is assumed to be composed of a present tense and a modal (i.e. woll + pres). The present tense operator that attaches to the future modal is proposed to be able to "license" present morphology on a lower clause in the same way that past does. On this approach, Ogihara (1996) suggests we must imagine that the LFs that correspond to (1) and (2) are like Figure 26, in which the adjunct clause scopes below the matrix tense operator, contrary to what I have proposed. This is because a matrix tense can only transmit its features to elements in its c-command domain.

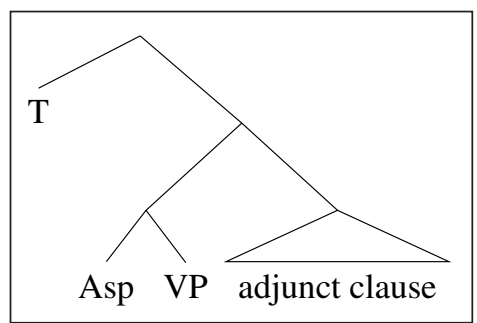

(1)

I adopted a cat after Katie left.

[ past I adopt a cat [ after ?? Katie leave ]]

I will adopt a cat after Katie leaves.

[ woll-pres I adopt a cat [ after ?? Katie leave ]] $\uparrow$

Ogihara notes, however, that this type of approach faces serious difficulty: treating adjunct tenses as morphologically licensed by a matrix tense fails to explain key contrasts between the adjunct present in (2) and other subordinate clauses. While some authors have worked to address some of these problems, I will argue that no approach of this type can easily explain both the future non-perfect and the future perfect examples.

There are two different formalisms of SOT that I know of, both of which have been explored for adjunct tenses and which make different predictions. One approach, adopted by von Stechow \& Grønn (2013), is called the feature transmission view of SOT, in which the embedded past in (57) is a present tense operator concealed by past morphology. The past feature observed in the subordinate clause is transmitted through binding by the higher past operator.

Another approach, adopted by Sharvit (2013), is called the deletion view of SOT, in which the embedded past in (57) is a deleted past operator, licensed by a c-commanding past. Deletion
Glossa: a journal of

general linguistics

DOI: $10.5334 / \mathrm{gjgl} .1429$
Figure $26 \mathrm{An}$ LF in which SOT accounts for the observed adjunct tenses in (1) and (2). 
of a past operator amounts to deleting its evaluation index, making it vacuous like the English present. The evaluation indices of lower operators in the embedded clause are thus bound as though there were no tense head, thus resulting in a simultaneous interpretation. On the deletion view, the simultaneous reading is a feature of the SOT mechanism, while on the feature transmission view, it is a by-product of the fact that the only possible concealed tense in this context is a present.

(57) Katie believed that her cat was angry. (simultaneous version)

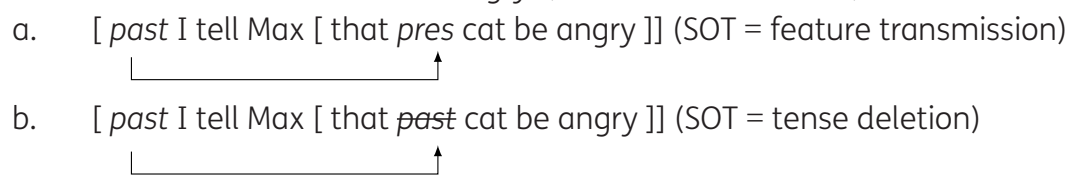

The first problem that these approaches face is the apparent non-optionality of SOT in temporal adverbial clauses. In other subordinate adjunct clauses such as relative clauses, ambiguity afforded by the SOT theory in past contexts is realized as separate adjunct tenses in future contexts. If SOT applies, it apparently does so optionally, since (a) (58a) is ambiguous, and (b) morphological uniformity between the matrix and adjunct clause is not enforced in (58b).
a. I gave Katie the cat that she liked. (ambiguous)
SOT applies: Katie likes the cat at the time of giving
SOT does not apply: Katie liked the cat before the time of giving
b. I will give Katie the cat that she likes/liked.

Since SOT is not generally enforced in independent contexts, something needs to be added to the theory to explain why adjunct tenses in (1) and (2) are uniformly determined by matrix tense. In particular, why can't we pronounce adjunct past in a future context, as in (46), as we can in (58b)? According to the LF in Figure 26, the adjunct past should be interpreted with respect to a future time, which is compatible with the truth conditions of after clauses.

$$
{ }^{*} \text { I will adopt a cat after Katie left. }
$$

The puzzle that (46) poses is different for each type of SOT approach. On the feature transmission view, either present or past morphology should be licensed in future after clauses, where the choice does not affect interpretation. Due to the fact that the adjunct predicate is eventive, and there are no "deleted" present tenses on this view, the only LF that is compatible with the truth conditions of after clauses contains a relative adjunct past. Whether this past tense is concealed by present morphology should be optional if feature transmission is an optional process, thus failing to predict the ill-formedness of (46).

$$
\begin{aligned}
& \text { LF for future after clauses: [ I will adopt a cat [ after PST Katie leave ]] } \\
& \text { SOT applies (2): "I will adopt a cat after Katie leaves." } \\
& \text { SOT does not apply (46): "I will adopt a cat after Katie left." }
\end{aligned}
$$

Adopting the condition on redundancy proposed in this paper would not resolve this issue because it would rule out the only viable LF on this theory. In order for a feature transmission SOT approach to work, it would therefore need an additional condition on pronunciation to rule out adjunct past in (46) compared to (58b). ${ }^{9}$

On a deletion view, (46) is puzzling for a different reason. On this theory, two LFs are in principle available for an after clause in a future context, one with a relative adjunct past and one with a relative adjunct present. The LF that contains adjunct present corresponds to (2) and requires SOT to apply because an interpreted adjunct present shouldn't be available for an eventive predicate (assume for the sake of argument that a deleted present can integrate into the meaning of after clauses without a simultaneous interpretation).

9 It is also not obvious to me that the present morphology on likes in (58b) is ambiguous in the way that the theory predicts. If SOT can't be independently observed in future contexts outside of examples like (2), this poses another problem for the SOT approach. 
a. [ I will adopt a cat [ after pRs Katie leave ]] SOT applies (2): "I will adopt a cat after Katie leaves."

b. [I will adopt a cat [ after PSt Katie leave ]]

SOT does not apply (46): "I will adopt a cat after Katie left."

However, this theory says nothing about the LF that contains an adjunct past because the structural description for SOT is not met in that case. Sharvit (2013) therefore proposes that a condition on redundancy rules out (46), leaving deleted present as the only possible realization of tense in the adjunct clause.

The crucial problem for both of these approaches is that adjunct past is available in future perfect contexts. As we saw in Section 2, adjunct past and present perfect in (16) behave as though they are interpreted with respect to the output of tense, i.e. as though they are interpreted according to the LF in Figure 27.

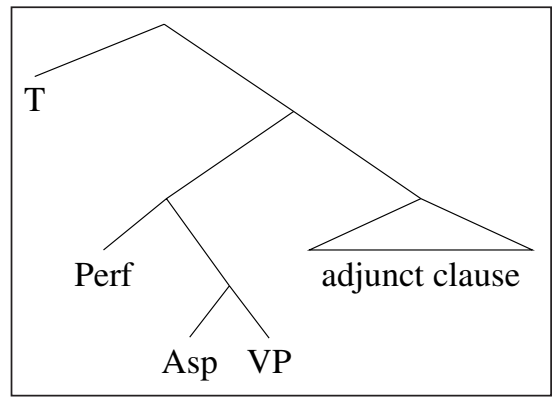

Figure 27 An LF that accounts for the interpretation of past/ present perfect in (16).

Context: my mom plans to visit me twice before the year is over, and her first visit is scheduled to follow my future purchase of a new bike.

a. By this time next year, mom will have visited twice since I bought/*buy my new bike.

b. ?By this time next year, mom will have visited twice since I've been riding my new bike.

If the LF in Figure 27 is right, it poses an immediate problem for SOT approaches because this is supposed to be the same LF that licenses SOT present in the adjunct clause. Despite this, simple present morphology is patently ruled out in (16), which therefore falsifies the predictions of the theory.

One could try to argue against the LF in Figure 27. For example, one could propose that the adjunct clause in (16) is interpreted below the perfect. On this amendment to the theory, the adjunct past and present perfect couldn't be interpreted or else the result would be either contradictory or simply the wrong meaning. This problem could be rectifiable, however, if the adjunct past and present perfect were also vacuous tenses licensed by an SOT rule. The perfect has been shown to license a vacuous past in embedded clauses.

a. John believes Mary to have claimed that she was in the wrong. (Ogihara 1996: 131)

Simultaneous reading: Mary's claim is "I am in the wrong".

b. John has often believed/thought/said that he was unhappy. (Stowell 2007: 15) Simultaneous reading: John's utterance is "I am unhappy".

While the perfect may license a vacuous past (via an SOT rule), it doesn't seem to license simultaneous interpretations of embedded present perfect. The fact that adjunct tense shows signature properties of relative tenses in future perfect contexts therefore presents a serious challenge to SOT analyses of adjunct tense in English.

\footnotetext{
a. John believes Mary to have claimed that she has been in the wrong. (doesn't mean Mary claimed "I am in the wrong")

b. John has often believed/thought/said that he has been unhappy. (doesn't mean John has said "I am unhappy")
} 


\section{CONCLUSION}

This paper began with an empirical enrichment to the study of English temporal adjunct tenses. Previous literature proposed analyses of English temporal adjunct tenses on the basis of examples like (1) and (2), which suggest that adjunct tense is always past when the matrix tense is past, and present when the matrix tense is future. However, we observed that this generalization only holds in matrix non-perfect contexts. In matrix future perfect contexts, adjunct past is available, and has a relative interpretation.

Based on the profile of temporal adjunct tenses in future perfect contexts, I have argued that English adjunct tense is in principle sensitive to matrix temporal operators for interpretation; however, temporal adjunct tenses are often interpreted with respect to the utterance time due to the meanings of temporal adverbials, which require their complements to be interpreted in a higher structural position than their base adjunction site.

When the matrix clause is a non-perfect, the number of possible adjunction positions between an adjunct's base position and the highest temporal operator is fewer than that in a corresponding perfect clause. The result is that there are no meaningful adjunction sites below matrix tense where an adjunct tense can be interpreted in examples like (1) and (2), thus resulting in adjunct tenses that are necessarily interpreted with respect to the utterance time.

When the matrix clause contains a perfect, however, an adjunction position is made available below matrix tense, where a relative adjunct past can be interpreted, even if the adjunct event occurs in the future. This prediction is borne out by the occurance of adjunct past in (3) and (16), which is interpreted relative to the output of tense.

The proposal relied on the assumption that adjunct clauses presuppose the truth of their clausal complements. The acceptability of a particular adjunct tense was therefore proposed to depend on a pragmatic condition that rules out contradictory or redundant interpretations. This pragmatic condition, combined with the distributional restrictions inherent to the temporal connectives themselves, heavily constrains the possible LFs associated with examples like (1), (2), (3), and (16).

With these assumptions, I demonstrated the full space of predicted adjunct tenses in perfect and non-perfect contexts for different temporal connectives and adjunction positions. ${ }^{10}$ For future perfect contexts, relative adjunct past was available for some combinations but not others, thus correctly predicting the fact that some temporal connectives seem to require adjunct past while others do not. Likewise, adjunct past was uniformly ruled out in the corresponding future non-perfects, thus correctly accounting for its absence in (2). In all the contexts where present (non-perfect) morphology is observed, adjunct future was predicted to be licensed, corroborating views of subordinative present as an underlying future tense (McCawley 1971; Comrie 1982; Dancygier 1998).

Lastly, this analysis was shown to be empirically more successful than SOT analyses of English adjunct tenses (e.g. Ogihara 1996; Sharvit 2013; von Stechow \& Grønn 2013). An SOT analysis of English adjunct tense would have required adjunct clauses to be interpreted within the scope of matrix $T$ in examples like (1) and (2), which fails to capture the relevance of the perfect in the matrix clause.

To situate this proposal into a broader discussion on adjunct tense interpretation, what makes temporal adverbial clauses special is that they contain the following ingredients: they're governed by an expression that encodes temporal ordering and is presuppositional, and they have the syntax of a clausal adjunct. Other adjunct clauses (e.g. relative clauses, because clauses, etc.) lack some of these ingredients and may have others that are missing in temporal adverbial clauses, and thus show a different profile with respect to adjunct tense interpretation. The syntax and morphology suggests that all of these adjunct clauses are built from the same

10 I have not demonstrated the predictions for matrix present contexts, but they should be the same as for matrix future contexts. Adjunct past is contradictory or redundant in present non-perfect contexts, but not in present perfect contexts.

(iv) a. I'm washing the dishes after we have/*had/*will have lunch.

b. (My hands are wet because) I'm washing the dishes before we have/*had $/{ }^{*}$ will have lunch.

c. I have been washing the dishes since I had/*have lunch. 
set of tense and aspect morphemes, so the semantics of those morphemes should be the same throughout. The different profiles of adjunct tenses must therefore be a product of the different syntactic configurations between adjunct and matrix clauses as well as the meanings of those clauses.

While this analysis has offered a unified account of temporal adjunct tenses in English, a reviewer notes that it raises puzzles for the cross-linguistic picture. In particular, temporal adjunct tenses in Japanese have been argued to behave more transparently like relative tenses, i.e. permitting adjunct past in future non-perfect after clauses, which was argued to be redundant (see Ogihara 1996; Sharvit 2013; von Stechow \& Grønn 2013 for discussion). It is unclear what accounts for this difference between English and Japanese without further investigation, but the following avenues of investigation are raised by the present theory. Recall that the analysis of English was based on a particular set of assumptions about the meanings of tense operators in English, combined with the conjecture that complements of temporal connectives can QR if they violate the pragmatic condition on redundancy/contradiction in situ. If in another language, the meanings of tense operators were different, or the complements of temporal connectives couldn't move for some reason, or the language offered a different strategy for ameliorating violations of this pragmatic condition, the picture would be different.

In sum, this paper has argued that temporal adjunct tenses in English are interpreted instead of vacuous, and constrained by the meanings of temporal connectives. The English perfect provided a testing ground in which to detect this behavior. Future research should investigate the cross-linguistic picture by finding analogous constructions to the English perfect in other languages and studying the behavior of temporal adjunct tenses in those contexts.

\section{ADDITIONAL FILE}

The additional file for this article can be found as follows:

- Appendix. A list of computations. DOI: https://doi.org/10.5334/gjgl.1429.s1

\section{ABBREVIATIONS}

FUT = future; IPFV = imperfective; $\mathrm{LB}=$ left boundary; $\mathrm{PFV}=$ perfective; $\mathrm{PRF}=$ perfect; PRS = present; $\mathrm{PST}=$ past; $\mathrm{RB}=$ right boundary; $\mathrm{SOT}$ = sequence of tense; $\mathrm{UT}$ = utterance time

\section{ACKNOWLEDGEMENTS}

I owe a great many thanks to Kai von Fintel, Sabine Iatridou, and Roger Schwarzschild for their boundless insight and encouragement on this project. I am additionally grateful to the audiences at LSA 2020 and MIT Ling Lunch, as well as two anonymous reviewers for their attention and feedback. All mistakes are my own.

\section{COMPETING INTERESTS}

The author has no competing interests to declare.

\section{AUTHOR AFFILIATIONS}

Elise Newman (D) orcid.org/0000-0001-7154-6922

MIT, US

\section{REFERENCES}

Altshuler, Daniel \& Roger Schwarzschild. 2013. Correlating cessation with double access. In Maria Aloni, Michael Franke \& Floris Roelofsen (eds.), Proceedings of the 19th Amsterdam Colloquium, 43-50. Arregui, Ana \& Kiyomi Kusumoto. 1998. Tense in temporal adjunct clauses. Proceedings of SALT 8. 1-18. DOI: https://doi.org/10.3765/salt.v8i0.2814

Beaver, David \& Cleo Condoravdi. 2003. A uniform analysis of 'before' and 'after'. Proceedings of SALT 13, 37-54. DOI: https://doi.org/10.3765/salt.v13i0.2899 
Chierchia, Gennaro. 2009. On the explanatory power of dynamic semantics. Handout from a talk at Sinn and Bedeutung 14

Comrie, B. 1982. Future time reference in the conditional protasis. Australian Journal of Linguistics 2. 143-152. DOI: https://doi.org/10.1080/07268608208599288

Condoravdi, Cleo. 2010. NPI licensing in temporal clauses. Natural Language and Linguistic Theory 28. 877-910. DOI: https://doi.org/10.1007/s11049-010-9115-z

Copley, Bridget. 2008. The plan's the thing: Deconstructing futurate meanings. Linguistic Inquiry 3(2). 261-274. DOI: https://doi.org/10.1162/ling.2008.39.2.261

Dancygier, Barbara. 1998. Conditionals and prediction. Cambridge: Cambridge University Press.

Dowty, David. 1979. Word meaning and Montague grammar. Dordrecht: Reidel. DOI: https://doi. org/10.1007/978-94-009-9473-7

Dowty, David R. 1982. Tenses, time adverbs, and compositional semantic theory. Linguistics and Philosophy 5. 23-55. DOI: https://doi.org/10.1007/BF00390692

Fox, Danny. 2008. Two short notes on schlenker's theory of presupposition projection. Theoretical Linguistics 34(3). 237-252. DOI: https://doi.org/10.1515/THLI.2008.016

Geis, Michael. 1970. Adverbial subordinate clauses in English. Cambridge, MA: MIT dissertation.

Heinämäki, Orvokki Tellervo. 1974. Semantics of English temporal connectives. Austin, TX: University of Texas at Austin dissertation.

Iatridou, Sabine. 2014. About determiners on event descriptions, about time being like space (when we talk), and about one particularly strange construction. Natural Language Semantics 22(3). 219-263. DOI: https://doi.org/10.1007/s11050-014-9105-5

Iatridou, Sabine, Elena Anagnostopolou \& Roumyana Izvorski. 2001. Observations about the form and meaning of the perfect. In Michael Kenstowicz (ed.), Ken Hale: A life in language, 189-238. MIT Press.

Jacobson, Pauline. 1995. On the quantificational force of english free relatives. In Emmon Bach, Eloise Jelinek, Angelika Kratzer \& Barbara Partee (eds.), Quantification in natural languages, vol. 2, 451-486. Dordrecht: Kluwer. DOI: https://doi.org/10.1007/978-94-017-2817-1_15

Kaufmann, Stefan. 2005. Conditional truth and future reference. Journal of Semantics 22(3). 231-280. DOI: https://doi.org/10.1093/jos/ffh025

Klein, Wolfgang. 1994. Time in language. New York: Routledge.

Kubota, Yusuke, Jungmee Lee, Anastasia Smirnova \& Judith Tonhauser. 2011. Cross-linguistic variation in temporal adjunct clauses. In Cahier chronos: Selected proceedings of chronos 8. 141-161. Amsterdam/Atlanta: Rodopi. DOI: https://doi.org/10.1163/9789401208345_009

Larson, Richard. 1984. Extraction and multiple selection in PP. Ms, MIT.

Mandelkern, Matthew \& Jacopo Romoli. 2017. Parsing and presuppositions in the calculation of local contexts. Semantics and Pragmatics 10(7). 1-41. DOI: https://doi.org/10.3765/sp.10.7

Mayr, Clemens \& Jacopo Romoli. 2016. A puzzle for theories of redundancy. Semantics and Pragmatics 9(7). 1-48. DOI: https://doi.org/10.3765/sp.9.7

McCawley, James D. 1971. Tense and time reference in english. In Charles Fillmore \& D. Terence Langendoen (eds.), Studies in linguistic semantics, 96-113. Holt.

McCoard, Robert W. 1978. The English perfect: Tense choice and pragmatic inferences. Amsterdam: North Holland Press.

Mittwoch, Anita. 1988. Aspects of English aspects: on the interaction of perfect, progressive, and durational phrases. Linguistics and Philosophy 11. 203-254. DOI: https://doi.org/10.1007/BF00632461

Moens, Marc \& Mark Steedman. 1988. Temporal ontology and temporal reference. Computational Linguistics 14(2). 15-28.

Ogihara, Toshiyuki. 1995. Non-factual before and adverbs of quantification. In T. Galloway \& M. Simons (eds.), Proceedings from SALT V, 273-291. Cornell University, Ithica, NY: DMLL Publications. DOI: https://doi.org/10.3765/salt.v5i0.2698

Ogihara, Toshiyuki. 1996. Tense, attitudes, and scope. Dordrecht: Kluwer. DOI: https://doi.org/10.1007/97894-015-8609-2

Reichenbach, Hans. 1947. Elements of symbolic logic. New York: Macmillan \& Co.

Romero, Maribel \& Arnim von Stechow. 2008. Tense: Introduction. Lecture Notes. Tübingen: University of Tübingen.

Schlenker, Philippe. 2009. Local contexts. Semantics and Pragmatics 2(3). 1-78. DOI: https://doi. org/10.3765/sp.2.3

Sharvit, Yael. 2013. On the universal principles of tense embedding: The lesson from before. Journal of Semantics 31. 263-313. DOI: https://doi.org/10.1093/jos/ffs024

Singh, Raj. 2007. Assertability constraints and absurd assertions. Ms, MIT.

Smith, Carlota. 1975. The analysis of tense in English. Texas Linguistic Forum 1. 71-89.

Stalnaker, Robert. 1978. Assertion. Syntax and Semantics 9. 315-332. DOI: https://doi. org/10.1163/9789004368873_013

Stowell, Tim. 2007. Sequence of perfect. In Jacques Moeschler Louis de Saussure \& Genoveva Puskas (eds.), Recent advances in the syntax and semantics of tense, mood and aspect, 123-146. Mouton De Gruyter. 
Stump, Gregory. 1985. The semantic variability of absolute constructions. Dordrecht: Reidel. DOI: https:// doi.org/10.1007/978-94-009-5277-5

Thomason, Richmond H. 1984. Combinations of tense and modality. In Dov Gabbay \& Franz Guenthner (eds.), Handbook of philosophical logic: Extensions of classical logic, 135-165. Reidel, Dordrecht. DOI: https://doi.org/10.1007/978-94-009-6259-0_3

Vlach, Frank. 1993. Temporal adverbials, tenses, and the perfect. Linguistics and Philosophy 19. 231-283. DOI: https://doi.org/10.1007/BF00985970

von Fintel, Kai \& Sabine Iatridou. 2019. Since since. In Daniel Altshuler \& Jessica Rett (eds.), The semantics of plurals, focus, degrees, and times: Essays in honor of Roger Schwarzschild, 305-333. Springer. DOI: https://doi.org/10.1007/978-3-030-04438-1_15

von Stechow, Arnim \& Atle Grønn. 2013. Tense in adjuncts part 2: Temporal adverbial clauses. Language and Linguistics Compass 7(5). 311-327. DOI: https://doi.org/10.1111/lnc3.12019

von Stechow, Arnim \& Sigrid Beck. 2015. Events, times and worlds: an LF architecture. In Christian Fortmann, Anja Lübbe \& Irene Rapp (eds.), The expression of time, 129-66. De Gruyter.

Wekker, Herman. 1977. Future reference in adverbial clauses in english. Interlanguage Studies Bulletin 2(3). 64-77. gessa: a journal of

general linguistics

DOI: $10.5334 / \mathrm{gjgl} .1429$
TO CITE THIS ARTICLE:

Newman, Elise. 2021. On the interpretation of tense in temporal adverbial clauses. Glossa: a journal of general linguistics 6(1): 12. 1-30. DOI: https://doi.org/10.5334/ gjgl.1429

Submitted: 05 September 2020 Accepted: 08 January 2021 Published: 03 February 2021

\section{COPYRIGHT:}

(c) 2021 The Author(s). This is an open-access article distributed under the terms of the Creative Commons Attribution 4.0 International License (CC-BY 4.0), which permits unrestricted use, distribution, and reproduction in any medium, provided the original author and source are credited. See http://creativecommons.org/ licenses/by/4.0/.

Glossa: a journal of general linguistics is a peer-reviewed open access journal published by Ubiquity Press. 